Archive for

Organic Chemistry
Arkivoc 2018, part i, 0-0

to be inserted by editorial office

\title{
Boric acid in organic synthesis: scope and recent developments
}

\author{
Rammohan Pal \\ Department of Chemistry, Acharya Jagadish Chandra Bose College, \\ 1/1B, A. J. C. Bose Road, Kolkata 700 020, India \\ Email:pal rammohan@yahoo.com
}

Received 12-31-2017

Accepted 03-30-2018

Published on line $\quad 05-28-2018$

\section{Abstract}

In recent years boric acid $\left[\mathrm{H}_{3} \mathrm{BO}_{3}\right]$ has played an important role in organic synthesis. The present review summarizes the latest developments in boric acid catalyzed transformations especially esterification, transesterification, aza-Michael and thia-Michael addition, condensation, Friedel-Crafts reactions, Tishenko reactions, halogenations, ipso substitution, decarboxylation, protection and deprotection reactions, amidation and transamidation reactions, multicomponent reactions including synthesis of nitrogen and oxygen heterocycles. Boric acid has emerged as an efficient, mild, commercially available, inexpensive catalyst in the formation of various biologically important organic compounds reported during the last decade.

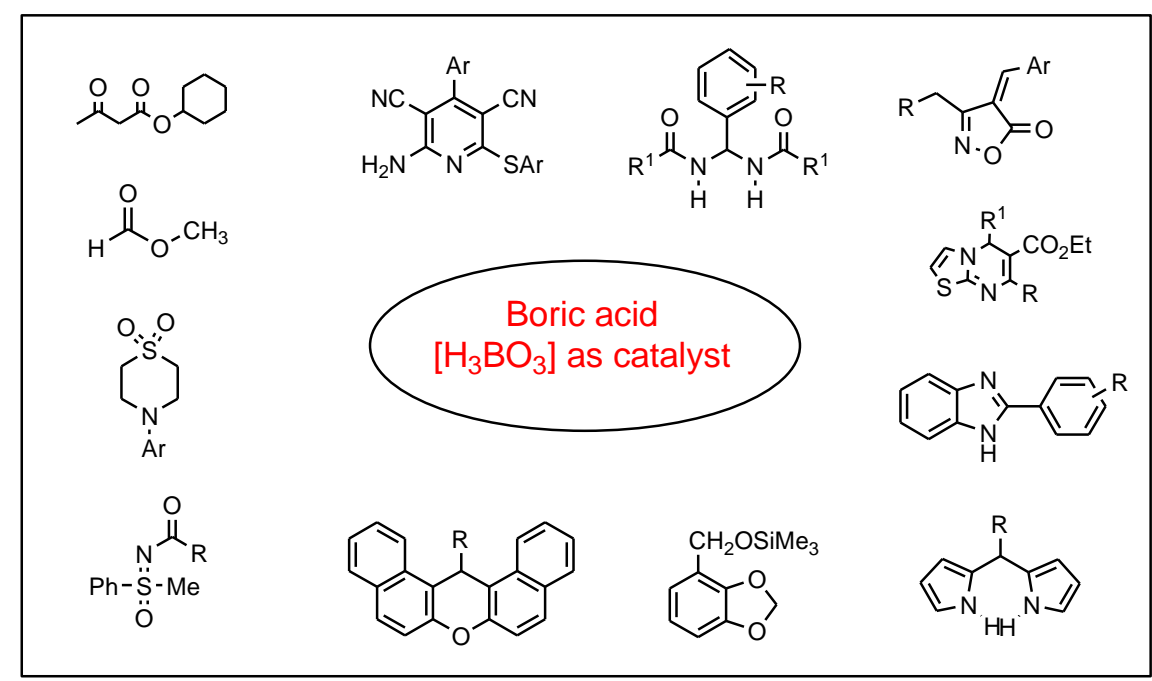

Keywords: Acid catalysis, boric acid, heterocycles, organic synthesis 


\section{Table of Contents}

1. Introduction

2. General Information and Structural Features of Boric Acid

3. Esterification Reactions

3.1 Esterification of carboxylic acids

3.2 Esterification of $\alpha$-hydroxy acids

3.3 Esterification of sugar acids

3.4 Polyesterification of monohydroxyethyl ester of dicarboxylic acids

4. Transesterification Reactions

5. Aza-Michael Addition Reactions

6. Thia-Michael Addition Reactions

7. Condensation Reactions

7.1 Condensation of carbonyl compounds and active methylene compounds

7.2 Condensation of carbonyl compounds and indole

7.3 Condensation of carbonyl compounds and pyrrole

8. Friedel-Crafts Reactions

8.1 Alkylation reactions

8.2 Acylation reactions

9. Tishchenko Reactions

10. Halogenation Reactions

11. Ipso Substitution Reactions

12. Decarboxylation Reactions

13. Protection and Deprotection Reactions

13.1 Protection of alcohols and phenols

13.2 Deprotection of alcohols and phenols

14. Amidation Reactions

15. Transamidation Reactions

16. Multicomponent Reactions

16.1 Ugi three-component reactions

16.2 Mannich reactions

16.3 Biginelli reactions

16.4 Synthesis of acetamidoketones

16.5 Formation of nitrogen heterocycles

16.5.1 Synthesis of benzimidazoles

16.5.2 Synthesis of benzodiazepines

16.5.3 Synthesis of fused pyrimidines

16.5.4 Synthesis of quinazolinones

16.5.5 Synthesis of imidazoles

16.5.6 Synthesis of pyridines

16.6 Formation of Oxygen Heterocycles

16.6.1 Synthesis of dibenzoxanthenes

16.6.2 Synthesis of benzopyrano-benzopyrans

17. Other Reactions 


\subsection{Synthesis of isoxazolinones}

17.2 Synthesis of aminophosphonates and aminonitriles

17.3 Synthesis of amidoalkyl-naphthols

18. Conclusions

19. Acknowledgements

References

\section{Introduction}

Over the past decade the chemistry of boric acid has undergone a rapid development. This growing interest is mainly due to its mild and highly selective properties, combined with its environmentally benign character and commercial availability. Boric acid is now routinely used in organic synthesis as effective acid catalysts for various selective transformations of simple and complex molecules. The purpose of the present review is to summarize the utility of boric acid with emphasis on recent synthetic applications. Literature coverage is through to the end of 2017.

\section{General Informations and Structural Features of Boric Acid}

Boric acid is a weak inorganic acid, and is also called boracic acid or orthoboric acid. It is a white crystalline solid having the following physical properties:

Chemical formula : $\mathrm{H}_{3} \mathrm{BO}_{3}$ or $\mathrm{B}(\mathrm{OH})_{3}$

Molar mass: $61.83 \mathrm{~g} / \mathrm{mol}$

Density $1.435 \mathrm{~g} / \mathrm{cm}^{3}$

Melting point: $170.9^{\circ} \mathrm{C}\left(339.6^{\circ} \mathrm{F} ; 444.0 \mathrm{~K}\right)$

Boiling point : $300{ }^{\circ} \mathrm{C}\left(572{ }^{\circ} \mathrm{F} ; 573 \mathrm{~K}\right)$

$p K_{a}: 9.24,12.4,13.3$

Solubility : Soluble in water and in lower alcohols; moderately soluble in pyridine; very slightly soluble in acetone

Figure $1 \mathrm{~A}$ shows that the central boron atom is connected to three hydroxy $(-\mathrm{OH})$ groups, which are capable of strong hydrogen bonding. Its solid crystalline structure consists of parallel layers of boric acid held together by hydrogen bonds (Figure 1B). It serves as a source of weak monobasic acid. It has been used in various acid catalyzed reactions. It is easy to handle, and safe to use, as a low concentration of boric acid does not pose any toxicity. It is also used as an antiseptic agent, in acne treatment, as preservative, insecticide, $\mathrm{pH}$ buffer, as swimming pool chemical and a precursor to many useful chemicals. 


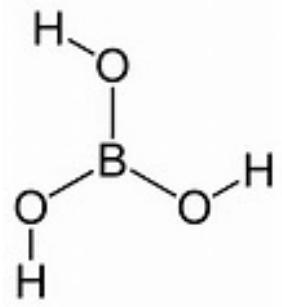

A

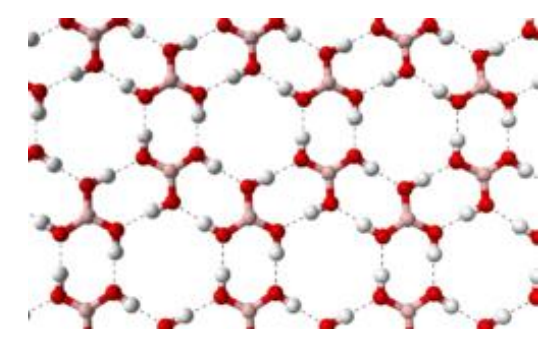

$\mathbf{B}$

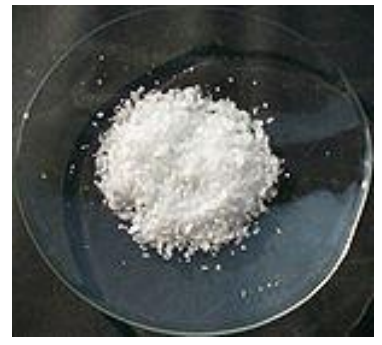

C

Figure 1. Structure of boric acid (A), parallel layers in solid state (B) and view of crystalline state (C).

\section{Esterification Reactions}

Esterification is one of the oldest, most widely used and most important chemical transformations in organic synthesis, with wide applications in chemical industries, pharmaceuticals, foods, perfumes and cosmetics. These reactions are applied to natural products synthesis, in protection or kinetics resolution of carboxylic acids and in intramolecular reactions to prepare lactones. Esterification of carboxylic acids, hydroxy acids, sugar acids has been studied using boric acid.

\subsection{Esterification of carboxylic acids}

Aliphatic and aromatic carboxylic acids undergo direct esterification reactions with phenols catalyzed by a combination of boric acid and sulfuric acid. Neither boric acid nor sulfuric acid alone catalyzes the reaction. Thus, phenyl benzoate (3) was produced in nearly quantitative yield when water is removed by azeotropic distillation from refluxing toluene containing phenol, benzoic acid, and a catalytic amount of boric acid and sulfuric acid (Scheme 1). ${ }^{1}$<smiles>O=C(O)c1ccccc1</smiles>

1<smiles>Oc1ccccc1</smiles>

2<smiles>O=C(Oc1ccccc1)c1ccccc1</smiles>

3

Scheme 1. Boric acid catalyzed esterification of carboxylic acid.

\subsection{Esterification of $\alpha$-hydroxy acids}

Chemoselective esterification of $\alpha$-hydroxy acids with boric acid was reported by Houston and co-workers. ${ }^{2}$ When malic acid (4) (a dicarboxylic acid which contains a hydroxyl group that is in the $\alpha$-position relative to one carboxylic acid and in the $\beta$-position relative to another) and methanol were allowed to react with boric acid overnight at room temperature, a high yield of monoester 5 was obtained (Scheme 2). The $-\mathrm{CO}_{2} \mathrm{H}$ group with respect to $\beta$-hydroxy group remained unchanged. The effect of $\alpha-\mathrm{OH}$ group relative to carboxylate was discussed. A five-membered cyclic neutral ester 6 and an anionic species 7 (Figure 2) may be formed during the reaction, accelerating the esterification reactions. 


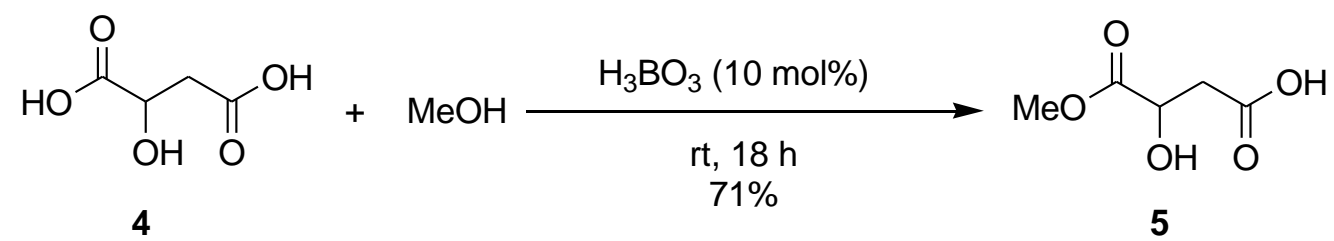

Scheme 2. Boric acid catalyzed methyl ester synthesis of $\alpha$-hydroxy acid.
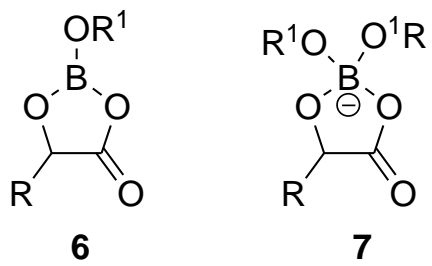

Figure 2. Compounds 6 and 7, possible intermediates in the esterification of an $\alpha$-hydroxy acid.

\subsection{Esterification of sugar acids}

Esterification of sugar acids with methanol has been accomplished in the presence of boric acid. Thus when sialic acid (8) (a sugar acid) was treated with anhydrous methanol in presence of catalytic amount of boric acid under nitrogen atmosphere at $50{ }^{\circ} \mathrm{C}$, methyl ester 9 was formed in $90 \%$ yield (Scheme 3). ${ }^{3}$ This reactions proceeded with high efficiency in certain sugar acid molecules but is highly substrate dependent. Glucuronic acid containing a $\beta$-hydroxycarboxylate motif, and the bacterial monosaccharide, 3-deoxy-D-manno-oct-2ulosonic acid (KDO) containing an $\alpha$-hydroxycarboxylate motif failed to esterify under boric acid catalysis in methanol.
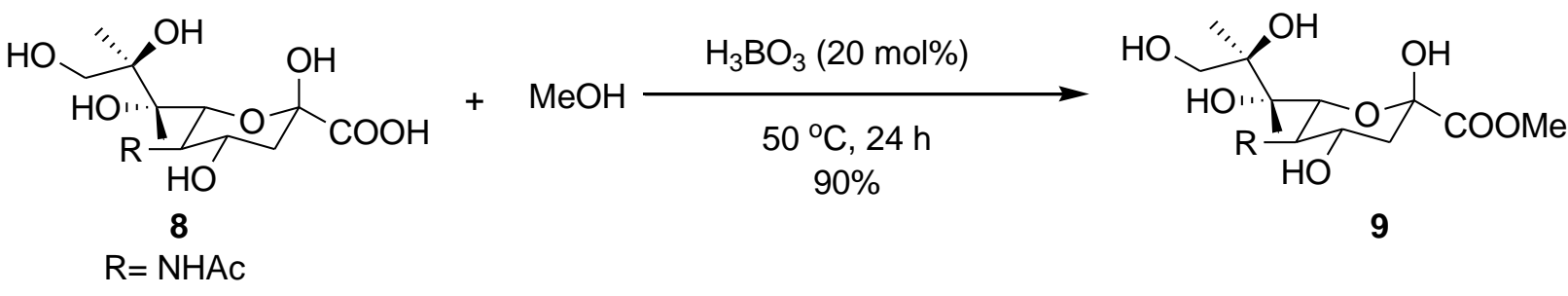

Scheme 3. Boric acid catalysis of sialic acid (8) esterification.

\subsection{Polyesterification of monohydroxyethyl ester of dicarboxylic acids}

Alemdar et al. ${ }^{4}$ found that boric acid-pyridine mixture works as an mild catalyst for polyesterification of the monohydroxyethyl esters of succinic acid 10, maleic acid $\mathbf{1 1}$ and phthalic acid $\mathbf{1 2}$. The catalyst system was demonstrated to give colorless polyesters 13, 14, 15 of low molecular weights (M: 1650-1950) within $4 \mathrm{~h}$ at $130{ }^{\circ} \mathrm{C}$ (Scheme 4). 


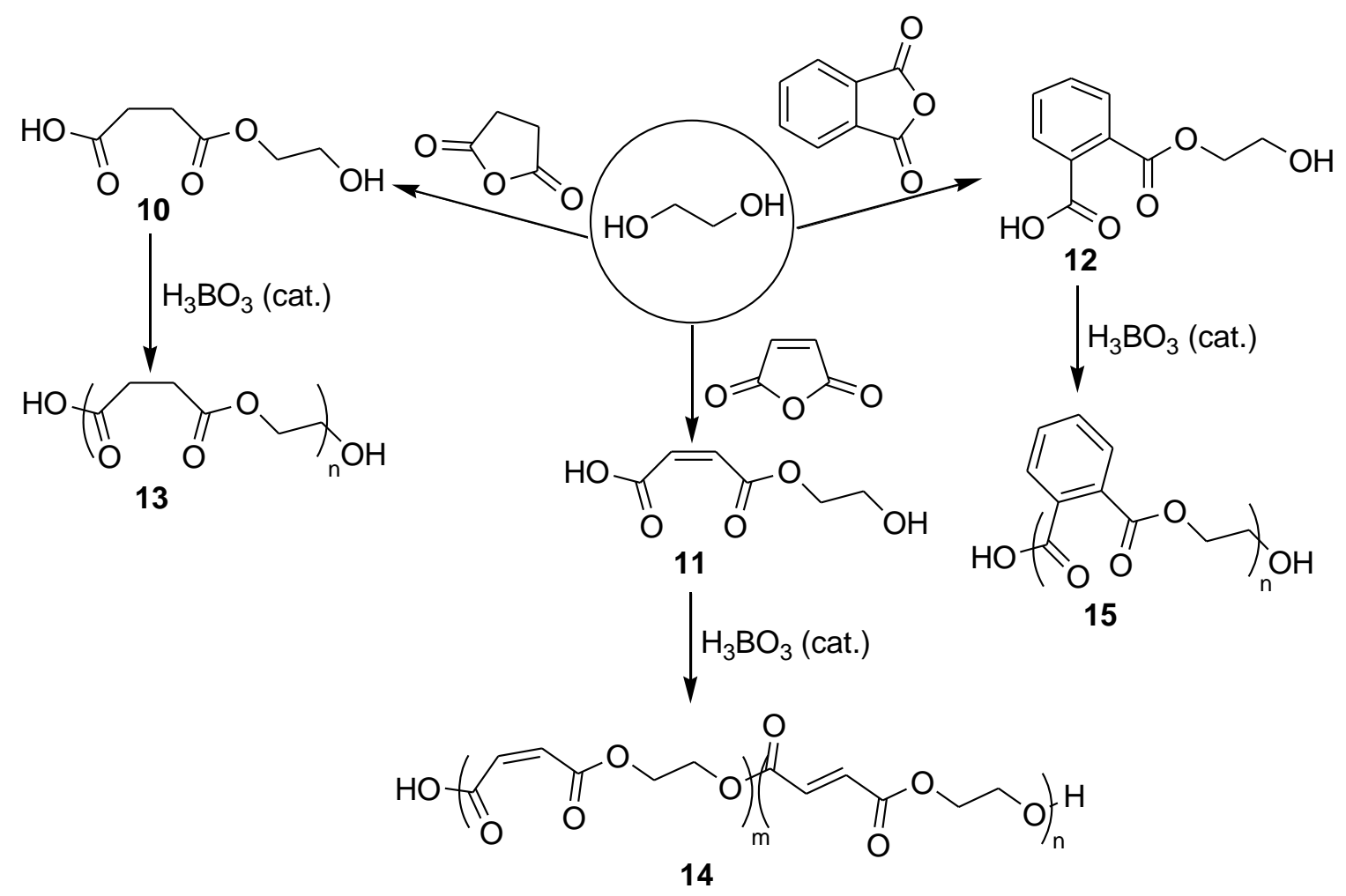

Scheme 4. Polyesterification of the monohydroxyethyl esters of 10, 11 and 12 with boric acid.

\section{Transesterification Reactions}

Transesterification of esters with alcohols have been reported using boric acid. Kondaiah and co-workers reported that boric acid acts as an environmentally benign catalyst for transesterification of ethyl acetoacetate (16) with a variety of alcohols including allylic alcohols, propargyl alcohols and sterically hindered primary and secondary alcohols in good to excellent yields. In a specific example, the transesterified $\beta$-ketoester 17 can be prepared from ethyl acetoacetate (16) and cyclohexanol using boric acid in refluxing xylene. (Scheme 5). ${ }^{5}$

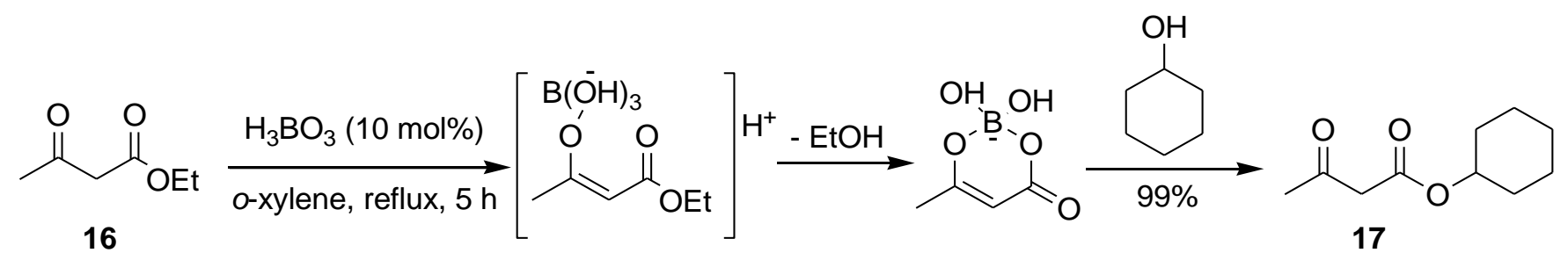

Scheme 5. Postulated mechanism of boric acid catalyzed transesterification reactions.

\section{Aza-Michael Addition Reactions}

Aza-Michael addition of aromatic amines to divinyl sulfone (18) and electron-deficient alkenes (20) has been accomplished in the presence of boric acid/glycerol in water under reflux to obtain the corresponding addition 
products in good to excellent yields without polymerization. The method can thus be used to produce $\mathrm{N}$ substituted thiomorpholine-1,1-dioxides 19 and $\beta$-amino esters/ketones/nitriles $\mathbf{2 1}$ from compounds 18 and 20 respectively (Scheme 6). ${ }^{6}$

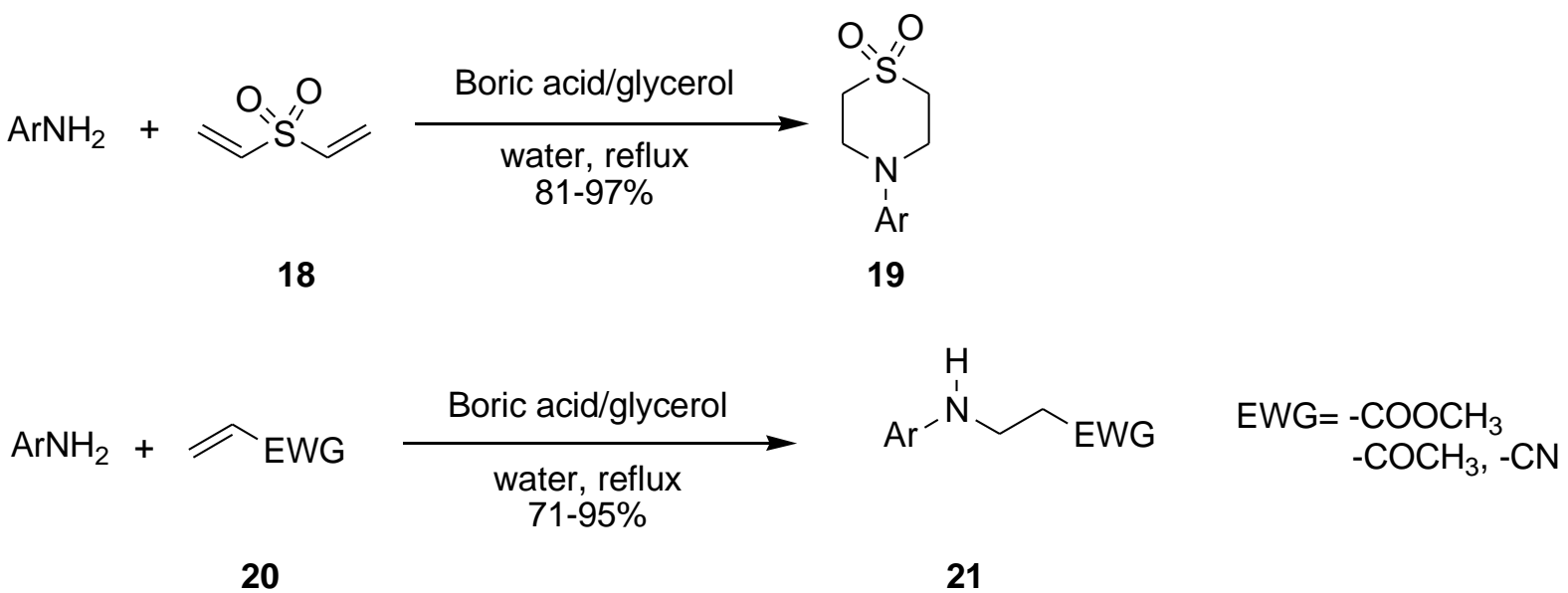

Scheme 6. Boric acid catalyzed aza-Michael addition reactions.

Chaudhuri et al. used primary and secondary aliphatic amines as Michael donors with acrylate esters (22) in presence of boric acid (10 mol\%) in water at room temperature to afford the corresponding aza-Michael addition product 23 in moderate to high yield (Scheme 7). ${ }^{7}$

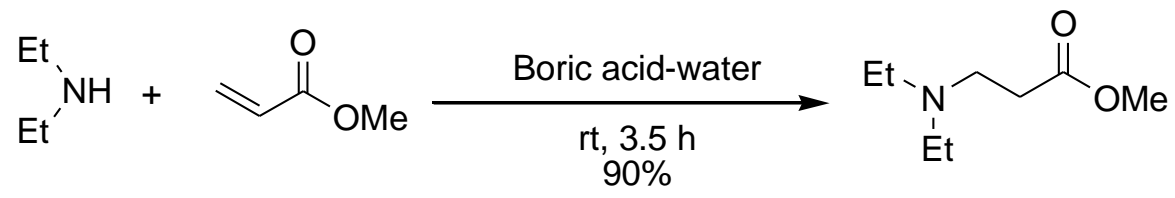

22

23

Scheme 7. Boric acid catalyzed aza-Michael addition of amine to $\alpha, \beta$-unsaturated ester.

\section{Thia-Michael Addition Reactions}

Aliphatic and aromatic thiols undergo thia-Michael addition reactions to $\alpha, \beta$-unsaturated nitriles, esters, ketones and aldehydes in presence of boric acid with very good yields in water at room temperature. The reactions are faster in $\mathrm{MeOH}$ or $\mathrm{EtOH}$ than water. Under similar experimental conditions, dithiols 24 underwent thia-Michael addition to $\mathbf{2 5}$ giving bis adduct $\mathbf{2 6}$ in good yields (Scheme 8). ${ }^{8}$

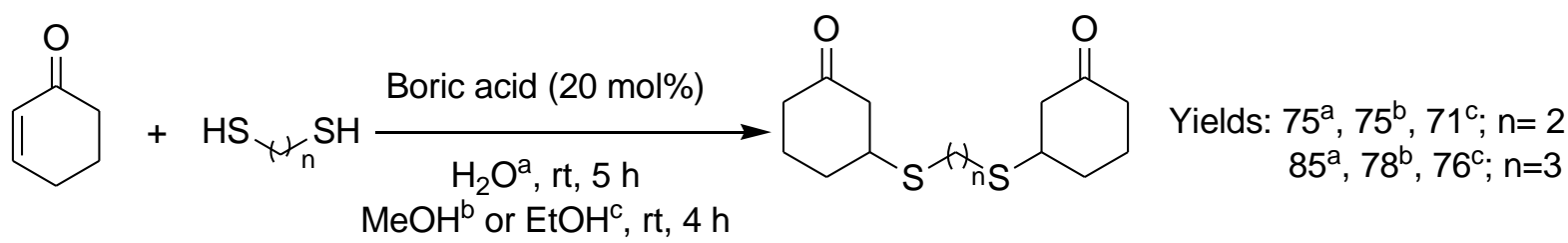

Scheme 8. Boric acid catalyzed thio-Michael addition of dithiols to $\alpha, \beta$-unsaturated ketone. 


\section{Condensation Reactions}

Cross-aldol condensation of aldehydes with ketones is an important synthetic reaction for the synthesis of $\alpha, \beta$ unsaturated carbonyl compounds, which are known to show diverse biological activities. ${ }^{9,10}$ These $\alpha, \beta-$ unsaturated carbonyl compounds are used as intermediates for the synthesis of various pharmaceuticals, agrochemicals and perfumes. ${ }^{11,12}$ Condensation of carbonyls with indoles give bis-(3-indolyl)methanes, and with pyrrole to give dipyrromethanes which show a wide variety of biological activities. ${ }^{13}$ It was found that boric acid effectively catalyzes the reactions.

\subsection{Condensation of carbonyl compounds and active methylene compounds}

Brun and his co-workers ${ }^{14}$ showed that boric acid can act as an efficient Lewis acid catalyst for the cross-aldol condensation reactions of acetophenone derivatives/activated methylene compounds with aldehydes under microwave irradiation under solvent free conditions. Thus, when compounds $\mathbf{2 7}$ and $\mathbf{2 8}$ were mixed thoroughly with boric acid, and the mixture was subjected to microwave irradiation, the condensation product 29 was produced smoothly in very good yields (Scheme 9).

Offenhauer and Nelsen ${ }^{15}$ have also cited boric acid to catalyze the aldol condensation of acetophenone and a variety of aliphatic and aromatic aldehydes and subsequent dehydration to form $\alpha, \beta$-unsaturated ketones in high yields.

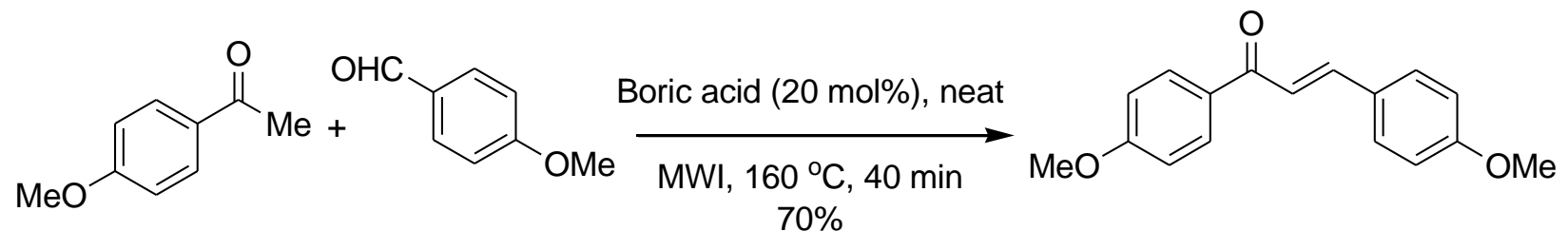

27

28

29

Scheme 9. Cross-aldol condensation reaction catalyzed by boric acid.

\subsection{Condensation of carbonyl compounds and indoles}

Meshram and his group observed that boric acid can be used in the condensation of indoles with aromatic aldehydes (30) for the synthesis of diindolylmethanes (31). Thus, when boric acid was added to a stirred solution of indole and an aromatic aldehyde in water at room temperature, $\mathbf{3 1}$ was formed in high yield within 20-40 min. (Scheme 10). ${ }^{16}$ The same condensation reaction was reported by Yadav et al. ${ }^{17}$ under solvent-free conditions.

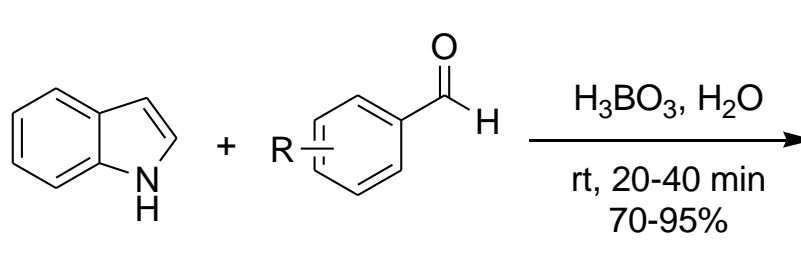

30

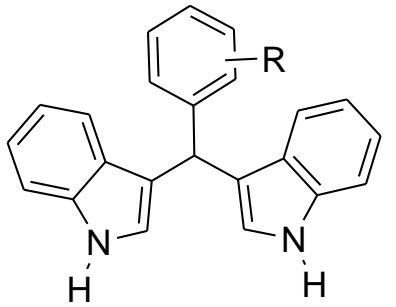

31

Scheme 10. Boric acid promoted condensation reactions between indole and aldehydes. 
Bisindolylmethanes and tetra-indolyl derivatives were synthesized by Kumar and his group by the condensation of indoles with mono-aldehydes $\mathbf{3 0}$ and di-aldehydes such as terephthalaldehyde, in a stirred mixture at room temperature using silica-supported boric acid to give bisindolylmethanes $\mathbf{3 1}$ and the tetraindole derivative 32 respectively (Scheme 11). ${ }^{18}$
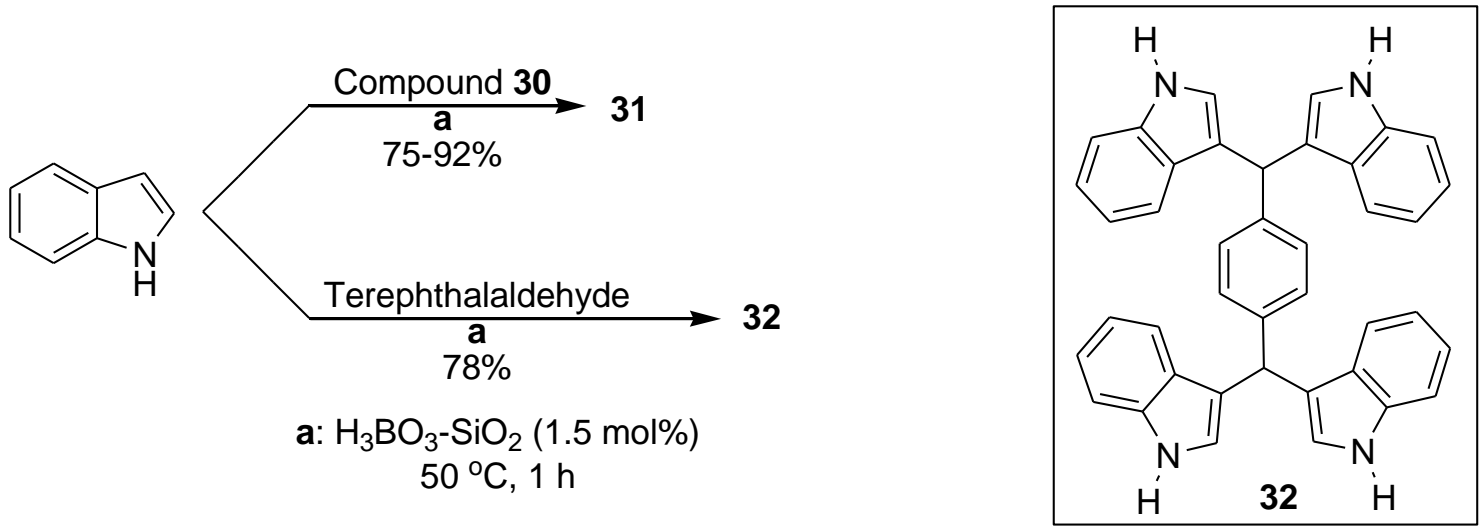

Scheme 11. $\mathrm{H}_{3} \mathrm{BO}_{3}-\mathrm{SiO}_{2}$ catalyzed condensation of aldehydes and indole.

\subsection{Condensation of carbonyl compounds and pyrrole}

A simple and efficient methodology catalyzed by boric acid was demonstrated by Pratibha ${ }^{19}$ for the synthesis of dipyrromethanes (33). Two equivalents of pyrrole and one equivalent of aldehyde gave $\mathbf{3 3}$ in good yield at room temperature when treated with boric acid in water (Scheme 12). The same condensation reaction was reported by Singhal et al. ${ }^{20}$, also in aqueous medium, using boric acid.

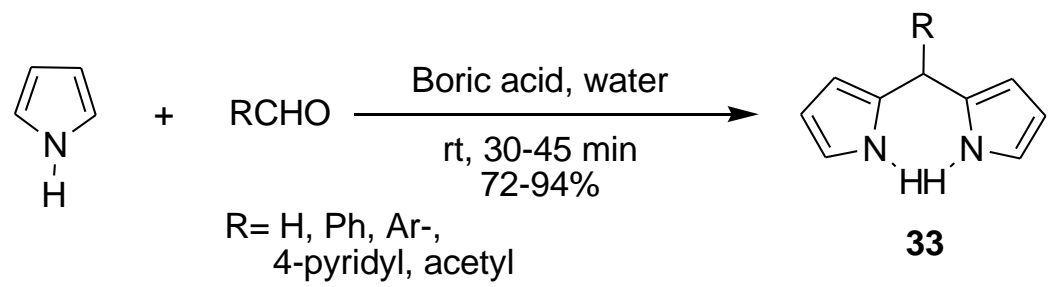

Scheme 12. Boric acid catalyzed synthesis of dipyrromethanes by condensation of pyrrole with aldehydes.

\section{Friedel-Crafts Reactions}

Friedel-Crafts reactions of aromatic and heteroaromatic compounds are one of the fundamental reactions for forming carbon-carbon bonds. ${ }^{21}$ Friedel-Crafts alkylation and acylation reactions have been studied using boric acid as an acid catalyst.

\subsection{Alkylation reactions}

Meshram et al. demonstrated that boric acid can act as a powerful catalyst for alkylation of activated heteroarenes and nitrostyrenes. Friedel-Crafts alkylations by various nitrostyrenes (34) were achieved on treatment with indoles using boric acid in water at room temperature to give the nitroalkylation products $\mathbf{3 5}$ in very good yields (Scheme 13). ${ }^{22}$ 
<smiles></smiles>

34

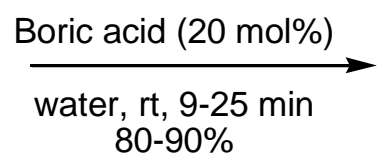
$80-90 \%$<smiles>[R]n1cc(C(CNO)C2C=CC=CC=C2)c2ccccc21</smiles>

35

$\mathrm{R}=\mathrm{H}, \mathrm{Me}$

$\mathrm{R}^{1}=\mathrm{H}, \mathrm{OMe}, \mathrm{NO}_{2}, \mathrm{Cl}, \mathrm{F}$

Scheme 13. Friedel Crafts alkylation of indoles with nitro olefins.

\subsection{Acylation reactions}

A series of $\mathrm{N}$-acylsulfoximines $\mathbf{3 7}$ were synthesized from sulfoximines (e.g. 36) with carboxylic acid by acylation reactions using boric acid in toluene under reflux conditions (Scheme 14). ${ }^{23}$ Boric acid forms an active acylating agent with the carboxylic acid, which reacts with $\mathbf{3 6}$ to produce acylation products $\mathbf{3 7}$ in $40-80 \%$ yields.

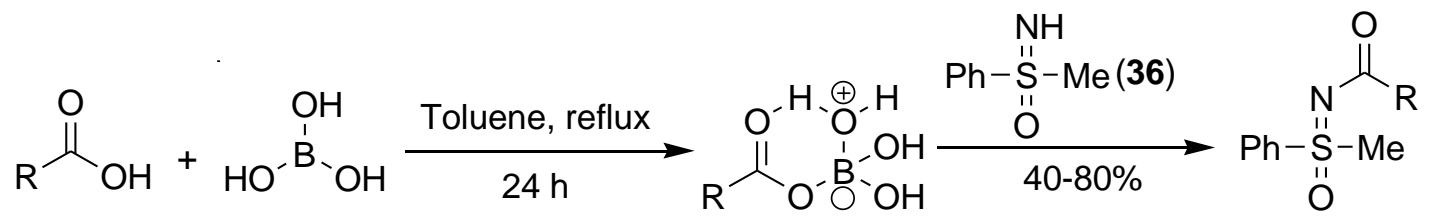

Scheme 14. Possible mechanism for boric acid catalyzed acylation of sulfoximines.

\section{Tishchenko Reactions}

It has been found that boric acid is an effective catalyst for the dismutation of certain aldehydes to the corresponding esters via a Tischenko-type reaction. When paraformaldehyde was heated with a catalytic quantity of boric acid in cyclohexane in an autoclave at $250^{\circ} \mathrm{C}$ for $5 \mathrm{~h}$, a $77 \%$ yield of methyl formate (38) was obtained (Scheme 15). ${ }^{24}$

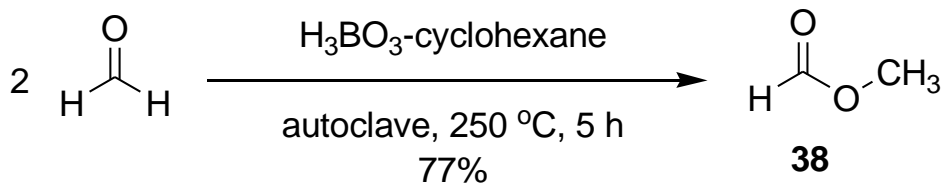

Scheme 15. Boric acid catalyzed Tishchenko reactions.

\section{Bromination Reactions}

A green protocol for the synthesis of bromo-organic compounds using boric acid as a recyclable catalyst with very high selectivity was reported by Nath and Chaudhury (Scheme 16). ${ }^{25}$ Substituted phenols, anilines, 
styrene, aromatic ketones, dibenzylideneacetone, and imidazole compounds undergo bromination reactions with $\mathrm{KBr}$ in water in the presence of $30 \% \mathrm{H}_{2} \mathrm{O}_{2}$ and a very small amount of $\mathrm{H}_{2} \mathrm{SO}_{4}$ and 5 mol\% boric acid. Since neither elemental bromine nor volatile organic solvents were used the authors claim it to be a non-toxic synthesis. 4,4'-dimethoxy-2'-hydroxychalcone $\mathbf{3 9}$ is selectively brominated at the olefinic double bond by this process. The brominated product $\mathbf{4 0}$ is an important precursor in flavonoid synthesis.

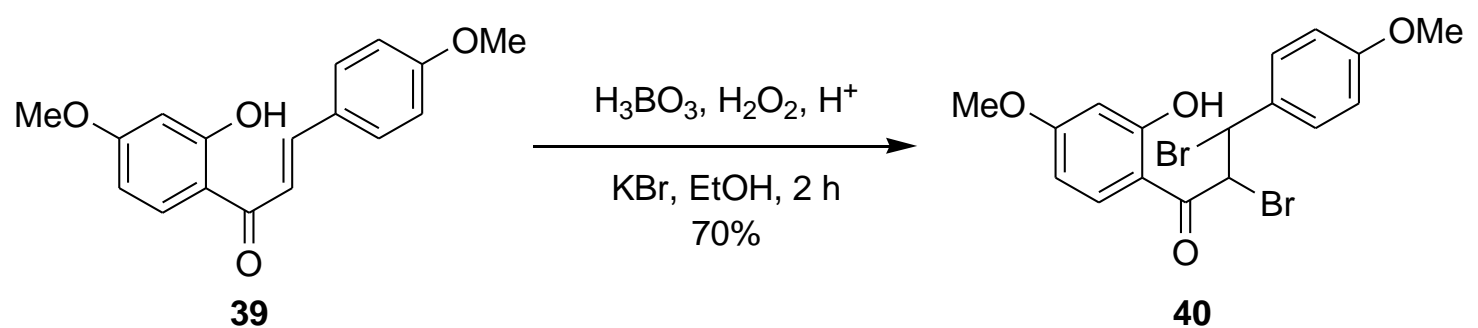

Scheme 16. Boric acid catalyzed selective bromination at the olefinic double bond.

\section{Ipso Substitution Reactions}

Ipso substitution reactions of arylboronic acid has been studied using boric acid as catalyst. Gogoi et al. ${ }^{26}$ have reported a simple and facile one-pot synthetic method of ipso hydroxylation of arylboronic acids $\mathbf{4 0}$ to the corresponding phenols $\mathbf{4 1}$ using boric acid as a green catalyst and aqueous hydrogen peroxide as an oxidizing agent in ethanol at room temperature (Scheme 17).

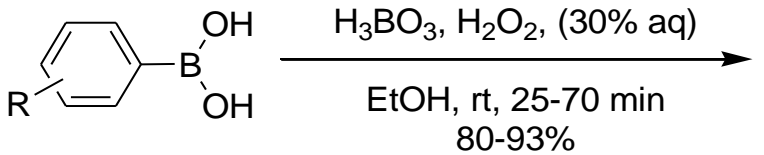

40<smiles>[R]c1ccc(O)cc1</smiles>

41
$\mathrm{R}=\mathrm{H}, \mathrm{Me}, \mathrm{OMe}, \mathrm{CN}$ $\mathrm{Cl}, \mathrm{NO} 2, \mathrm{~F}$, aryl

Scheme 17. Boric acid catalyzed synthesis of phenols by ipso substitution reactions.

\section{Decarboxylation Reactions}

Cyclic $\beta$-enaminones are important building blocks for synthesis of natural products like ipalbine, myrtine and methylpelletierine. Delbecq et al. reported that cyclic $\beta$-enaminones $\mathbf{4 3}$ could be prepared stereospecifically through decarboxylation of $\beta$-enaminoketoesters 42 by thermolysis in presence of boric acid (Scheme 18). ${ }^{27}$<smiles>[R]C(=O)C(C(=O)OC)=C1C[C@H]2CNC1C2</smiles>

42

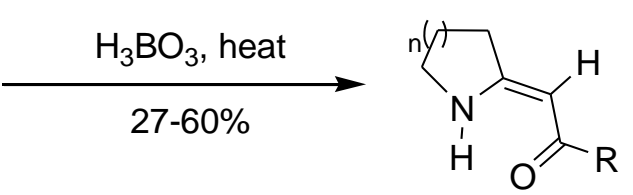

43

$$
\begin{aligned}
& \mathrm{n}=1,2,3 \\
& \mathrm{R}=\mathrm{CH}_{3}, \mathrm{C}_{3} \mathrm{H}_{7}, \mathrm{C}_{6} \mathrm{H}_{5}
\end{aligned}
$$

Scheme 18. Boric acid catalyzed decarboxylation of cyclic $\beta$-enaminoketoesters. 


\section{Protection and Deprotection Reactions}

Protection and deprotection reactions are very important and widely used strategy for organic synthesis. Reactions involving selective protection of functional groups such as alcohols, phenols, thiols and amines and their deprotections are common tools in the multi-step synthesis of complex natural products. ${ }^{28,29}$ Boric acid has been used as a green, selective and recyclable catalyst for protection of such functional groups by silylation and acetylation reactions and deprotection of trimethylsilyl ethers to their parent alcohols and phenols.

\subsection{Protection of alcohols, phenols, thiols and amines}

Rastomi and his co-workers reported that hydroxyl, thiol and amine groups can be protected by trimethysilylation process using catalytic amount of boric acid. Thus, when compound $\mathbf{4 4}$ was treated with hexamethyldisilazane (HMDS) in presence of boric acid in acetonitrile at room temperature, the corresponding silylated product 45 was obtained in $85 \%$ yield (Scheme 19). ${ }^{30}$ In case of thiols and amines, the reactions produced the corresponding silylation products in good yields under similar reaction conditions.

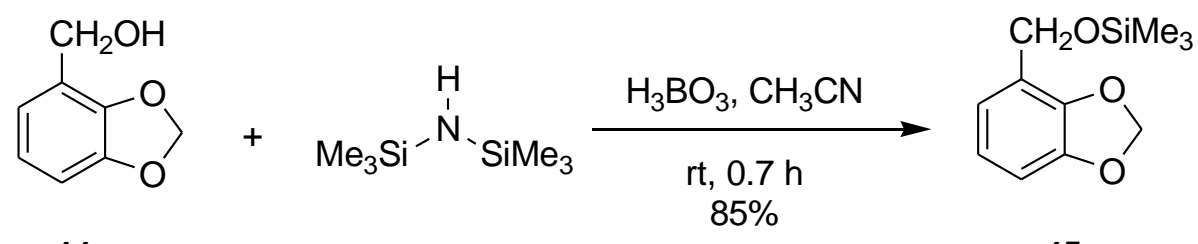

44

45

Scheme 19. Trimethylsilylation of alcohol catalyzed with boric acid.

Kumar et al. demonstrated that silica-supported boric acid works as an efficient catalyst for the chemoselective acetylation of amines. Thus, when tyramine 46 or 2-aminoethanol 47 were treated with acetic anhydride (1.1 equiv.) at $50{ }^{\circ} \mathrm{C}$ in presence of $\mathrm{H}_{3} \mathrm{BO}_{3}-\mathrm{SiO}_{2}$, a highly chemoselective acetylation of amino groups takes place, and the products $\mathbf{4 8}$ and $\mathbf{4 9}$ were obtained in excellent yields (Scheme 20). ${ }^{18}$

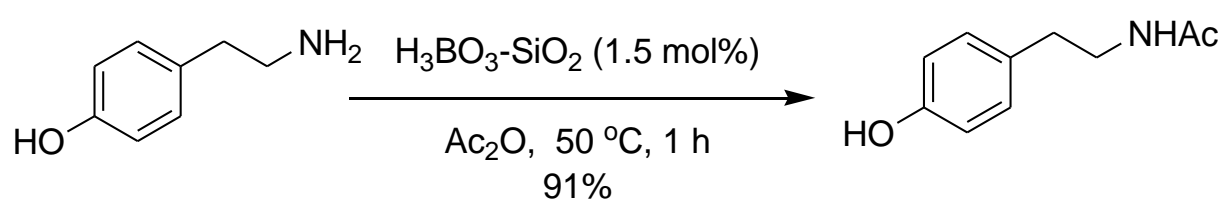

46

48

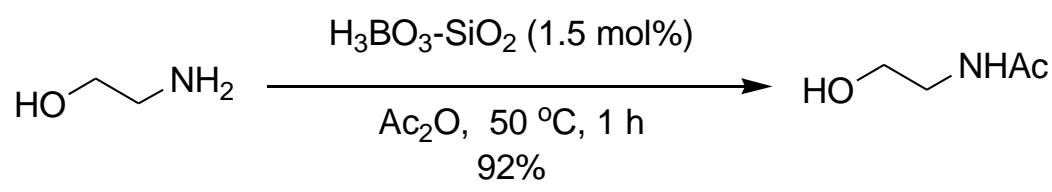

47

49

Scheme 20. Boric acid-silica catalyzed protection of amines $\mathbf{4 6}$ and $\mathbf{4 7 .}$ 


\subsection{Deprotection of alcohols and phenols}

The importance of the deprotection of trimethylsilyl ethers to their corresponding functional groups in multistep organic synthesis can not be overstated. Boric acid has been shown to catalyze such reactions efficiently to give good yields of the deprotected products. Trimethylsilyl ether of the type $\mathbf{5 0}$ was selectively deprotected to the corresponding phenol $\mathbf{5 1}$ using boric acid as catalyst in water at room temperature in $90 \%$ yield (scheme 21). ${ }^{30}$<smiles>COCc1cc(Br)cc(COC)c1OC</smiles>

50

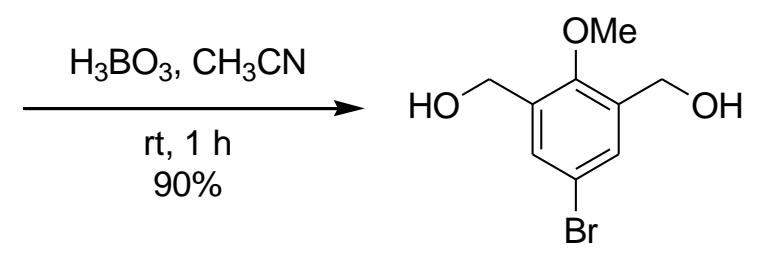

51

Scheme 21. Deprotection of trimethylsilyl ether catalyzed by boric acid.

\section{Amidation Reactions}

The thermal condensation of carboxylic acids and amines in presence or absence of catalysts / reagents are known as amidation reactions. Many synthetic methods have been developed in the past, for the synthesis of amides, which are important building blocks in a large number of natural products and active pharmaceuticals. $^{31,32}$ The classical amidation reactions which is carried out in absence of catalysts or reagents has traditionally been viewed as an unviable approach. The presumed formation of ammonium carboxylate salts, and extremely harsh conditions are required for the reactions to occur. Although there are several reports in the literature for amide formation, boric acid is found to be a suitable catalyst among them. Pingwah Tang reported in 2005, boric acid catalyzed direct amidation reaction of carboxylic acids and amines under anhydrous reaction conditions (Scheme 22). ${ }^{33}$ By means of catalytic boric acid in dry hydrocarbon solvents, several aliphatic and aromatic amides have been synthesized in moderate to good yields. N-Benzyl-4phenylbutyramide $\mathbf{5 4}$ could be synthesized in this process from 4-phenylbutyric acid $\mathbf{5 2}$ and benzylamine $\mathbf{5 3}$ in $99 \%$ yield.

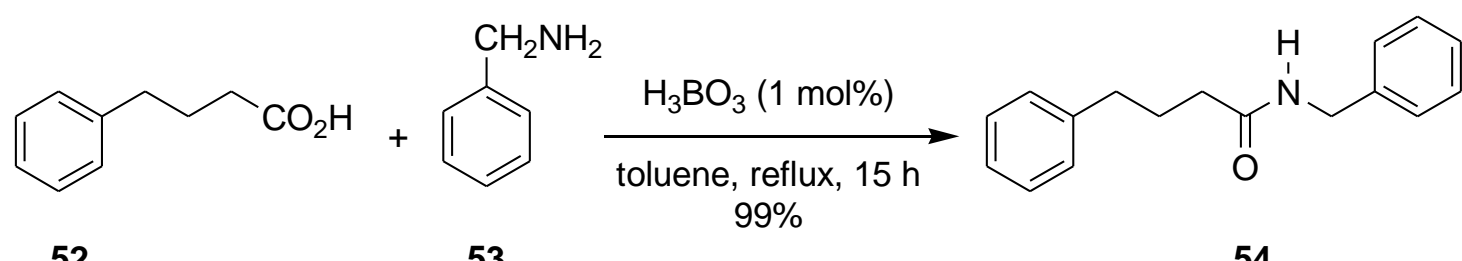

Scheme 22. Boric acid catalyzed amidation reacton of carboxylic acid and amine.

In a similar report Aree et al. described the $\mathrm{H}_{3} \mathrm{BO}_{3}$ catalyzed direct amidation of benzoic acid (55) and benzylamine (53) in dry toluene under reflux in $89 \%$ yields (Scheme 23 ). ${ }^{34}$ 
<smiles>O=C(O)c1ccccc1</smiles>

55

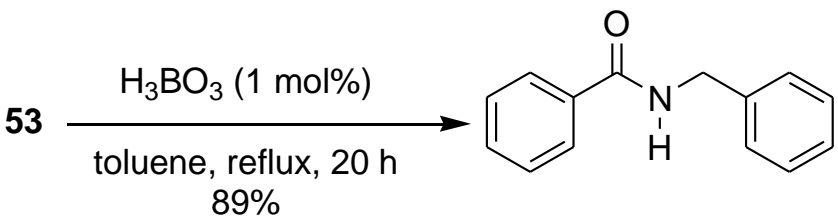

56

Scheme 23. Boric acid catalyzed amidation reaction of benzoic acid and benzylamine.

Similarly, Mylavarapu and coworkers successfully applied boric acid catalyzed conditions for the synthesis of carboxamides (59), key reaction intermediate in the preparation of various active pharmaceutical ingredients (APIs) in good yields (Scheme 24). ${ }^{35}$

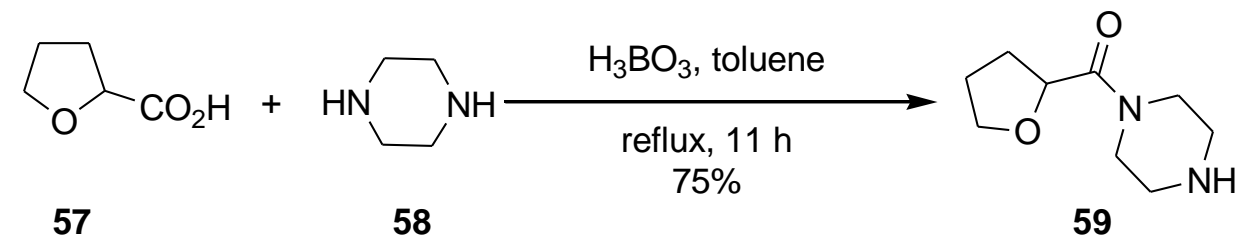

Scheme 24. Boric acid promoted synthesis of terazosin (API) by amidation.

Bisamides are important building blocks of many biologically active and pharmaceutical compounds, several synthetic methods for preparing these compounds have been developed in the past. A convenient preparation of symmetrical $\alpha$-bisamides 62 has been described from the condensation of aromatic aldehydes 60 and amides 61 in presence of boric acid as catalyst under thermal and neat microwave irradiation conditions in moderate to good yields (Scheme 25$).{ }^{36}$

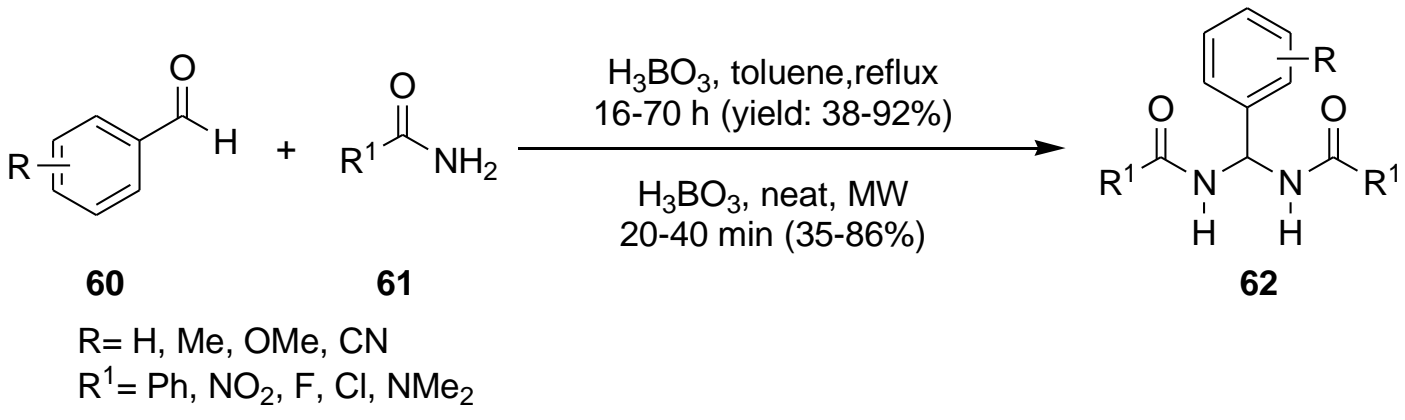

Scheme 25. Synthesis of various alkylidene bisamides catalyzed by boric acid.

\section{Transamidation Reactions}

Nguyen and his co-workers reported a novel method of transamidation of carboxamide 63 with amines 64 using boric acid. The scope of the methodology has been demonstrated with (i) primary, secondary, and tertiary amides and phthalimide and (ii) aliphatic, cyclic and acyclic, primary and secondary amines. Thus, when a mixture of $\mathbf{6 3}$ and $\mathbf{6 4}$ were heated with a catalytic amount of boric acid and water for a specified time, the transamidation products 65 were obtained in $42-90 \%$ yields (Scheme 26 ). ${ }^{37}$ 


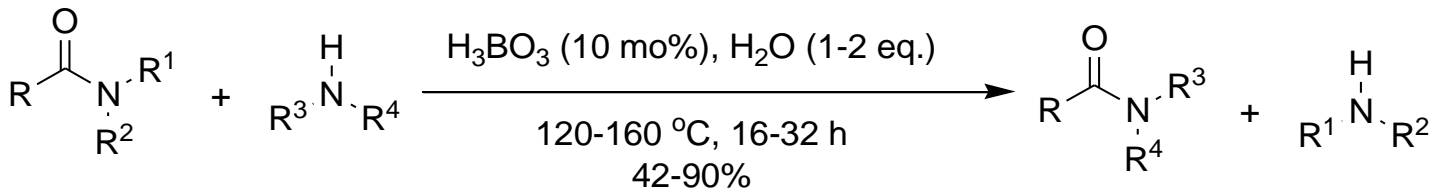

63
65

Scheme 26. Boric acid catalyzed transamidation of carboxamides and amines.

\section{Multicomponent Reactions}

Multicomponent reactions (MCRs) have recently gained much practical importance due to their speed, diversity and efficiency. ${ }^{38,39}$ MCRs are useful for the expedient creation of chemical libraries of drug-like compounds and optimization in drug discovery programmes. ${ }^{40}$

\subsection{Ugi Three-component reaction}

Kumar et al. reported an efficient one-pot Ugi three-component synthesis of 2-arylamino-2-phenylacetamide (66) from aldehydes, amines and isocyanides in water at room temperature using boric acid as catalysts (Scheme 27). ${ }^{41}$ Aromatic aldehydes containing either electron-donating or -withdrawing groups underwent the conversion smoothly. Several functional groups such as halogen $(\mathrm{Cl}, \mathrm{Br}), \mathrm{NO}_{2}$, ester and ether moieties were found to be stable under the reaction conditions.

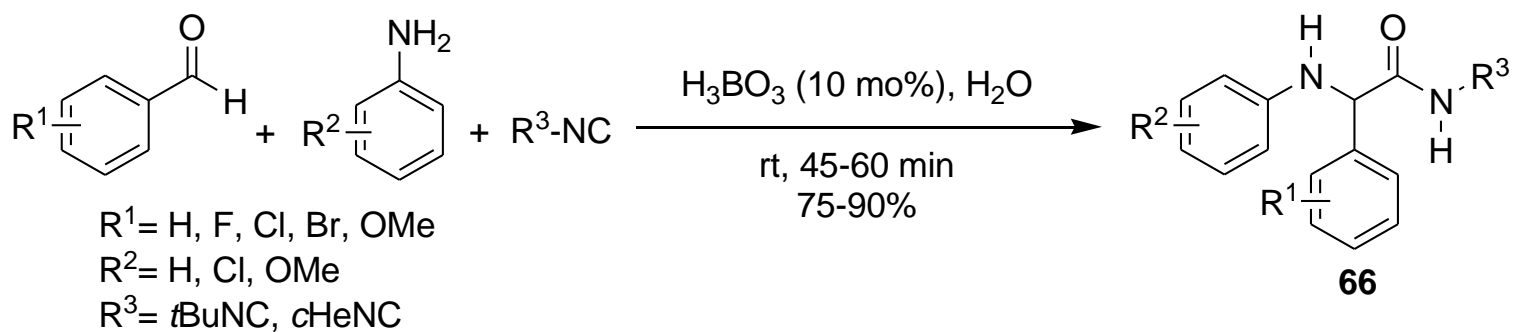

Scheme 27. Boric acid catalyzed Ugi-three component reactions.

\subsection{Mannich reactions}

$\beta$-Aminocarbonyl compounds $(67,68)$ were synthesized in a one-pot three component Mannich reaction of aromatic aldehydes, aromatic amines and cyclic ketones at ambient temperature catalyzed by boric acid and glycerol in water in good yields (Scheme 28). ${ }^{42}$ Syn diastereoselectivity was observed in major reactions. Boric acid and glycerol form a boron chelate complex (BCC) in water to release hydrogen ion and thus to increase the acidity of the medium which increased both the yield and diastereoselectivity of the Mannich reactions. 


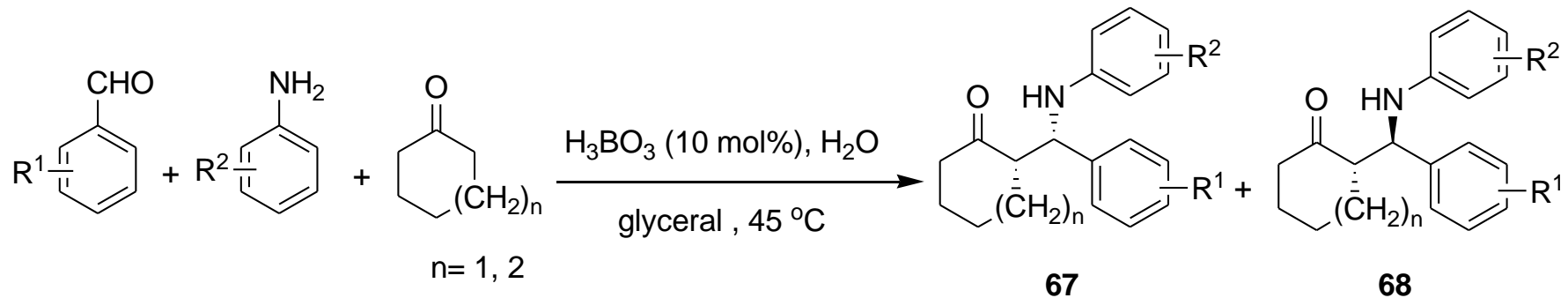

Scheme 28. Mannich reactions of aromatic aldehydes, aromatic amines and cycloalkanones catalyzed by boric acid and glycerol in water.

\subsection{Biginelli reactions}

Boric acid has also been used for Biginelli reactions, consisting of $\beta$-dicarbonyl compounds with dialdehydes and urea or thiourea to afford bis-dihydropyrimidinone derivatives $\mathbf{7 2}$ in presence of glacial acetic acid (Scheme 29). ${ }^{43}$ Tu et al. ${ }^{44}$ have also synthesized dihydropyrimidinone derivatives using boric acid as catalyst in a classical Biginelli reaction of aromatic aldehydes, 1,3-dicarbonyl compounds and urea in glacial acetic acid in excellent yields (86-97\%).

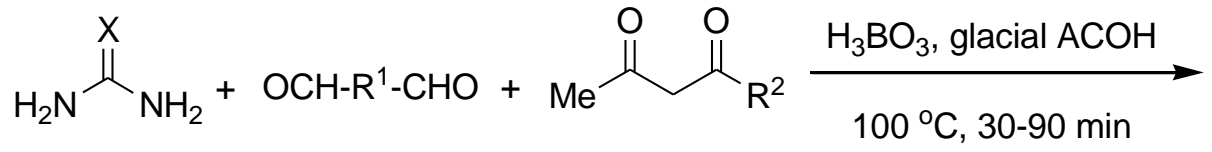

$$
\begin{aligned}
& 69 \\
& 70 \\
& 71 \\
& \text { 83-94\% } \\
& \mathrm{R}^{1}=\mathrm{C}_{6} \mathrm{H}_{4}- \\
& \mathrm{R}^{2}=\mathrm{Me}, \mathrm{OMe}, \mathrm{OEt} \\
& \mathrm{X}=\mathrm{O}, \mathrm{S}
\end{aligned}
$$<smiles>CC(=O)C1=C(C)NC(=O)NC1[R]C1NC(=O)NC(C)=C1C(C)=O</smiles>

72

Scheme 29. One-pot synthesis of bis-dihydropyrimidinones catalysed by boric acid.

\subsection{Synthesis of $\beta$-acetamido ketones}

A series of $\beta$-acetamidoketones $\mathbf{7 5}$ were synthesized from aromatic aldehydes $\mathbf{7 3}$, acetophenones $\mathbf{7 4}$ and acetonitrile by a one-pot three component reaction using boric acid as a solid heterogeneous catalyst at room temperature. Karimi-Jaberi and Mohammadi (Scheme 30) stated that boric acid was been used as a solid acid catalyst for the preparation of $\beta$-acetamido ketones for the first time. ${ }^{45}$<smiles></smiles>

73<smiles></smiles>

74

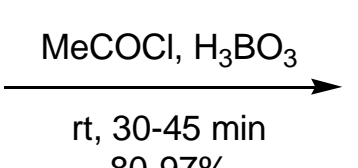

$80-97 \%$

$$
\mathrm{R}=\mathrm{R}^{1}=\mathrm{H}, \mathrm{Cl}, \mathrm{Me}, \mathrm{OMe}, \mathrm{NO}_{2}, \mathrm{OH}
$$

Scheme 30. One-pot synthesis of $\beta$-acetamido ketones using boric acid. 


\subsection{Formation of nitrogen heterocycles}

Nitrogen heterocycles form the backbone of a host of biologically active molecules. Benzimidazole ${ }^{46}$ and benzodiazepine ${ }^{47}$ systems are known to be important constituents of many pharmaceutical and agrochemical products. Fused pyrimidines have been used for vasorelaxant activity. ${ }^{48}$ Quinazolinone derivatives are interesting chemotherapeutic having anticancer and anti-HIV properties. ${ }^{49}$ Imidazole $^{50}$ and pyridine ${ }^{51}$ systems are one of the most important sub-structures found in a large number of natural products and pharmacologically active compounds. These important nitrogeneous heterocycles have efficiently been synthesized using as heterogeneous solid acid catalyst boric acid.

16.5.1 Synthesis of benzimidazoles. A series of substituted benzimidazoles 76 were synthesized by Rajala and Patil from the reactions between aromatic aldehydes and $o$-phenylenediamine using boric acid as a acid catalyst in water (Scheme 31). ${ }^{52}$ The catalyst was found to be most effective for the synthesis of quinolines in terms of reaction times, yields and cost consideration, over the other heterogeneous solid acid catalysts like $\mathrm{KHSO}_{4}$, ionic liquids and $\mathrm{Cu}(\mathrm{OTf})_{2}$. The same condensation reaction was reported by Heravi and Ashori using boric acid in water at room temperature. ${ }^{53}$

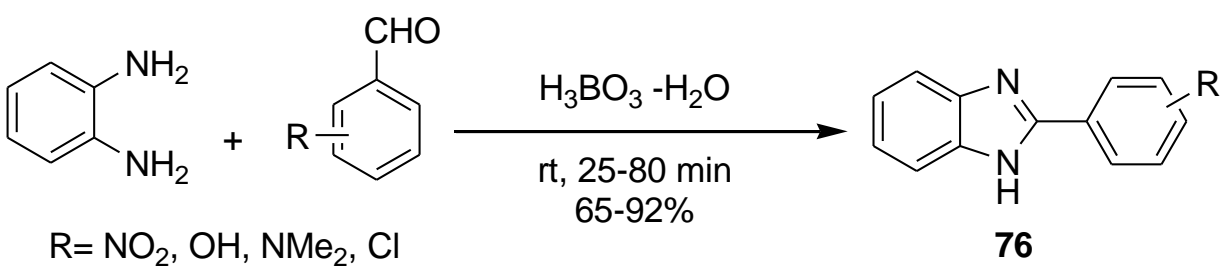

Scheme 31. Boric acid catalyzed synthesis of benzimidazoles in aqueous medium.

Maras and Kočevar reported a cyclocondensation reaction between substituted o-phenylenediamine 77 and carboxylic acids $\mathbf{7 8}$ to prepare a series of 2-substituted benzimidazoles $\mathbf{7 9}$ using boric acid as catalyst in toluene under reflux conditions (Scheme 32$).{ }^{54}$

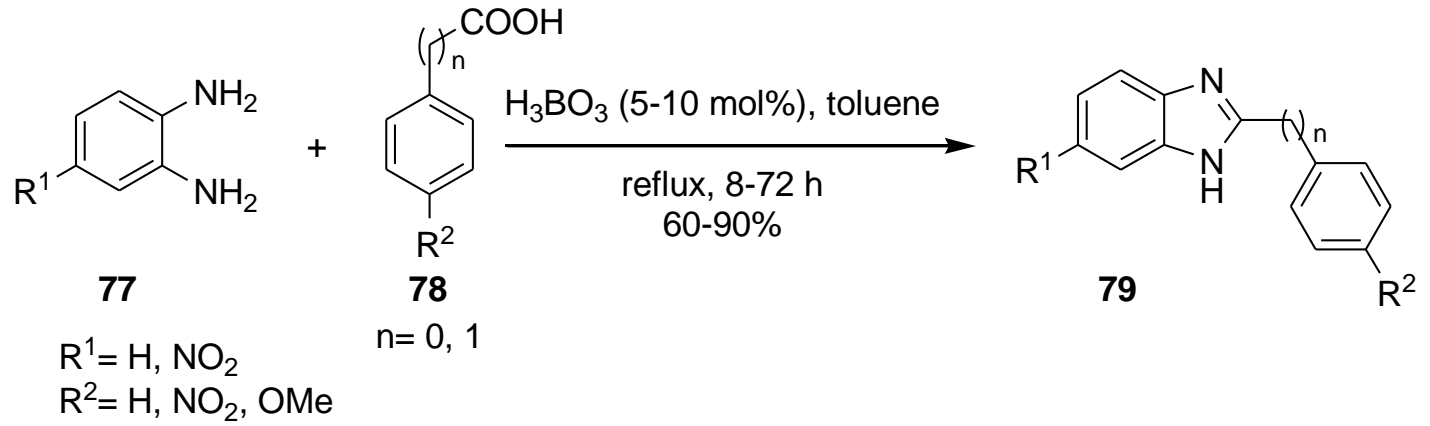

Scheme 32. Boric acid catalyzed condensation of carboxylic acid and o-phenylenediamine.

16.5.2 Synthesis of benzodiazepines. Zhou and co-workers have reported that boric acid acts as an excellent catalyst for the synthesis of benzodiazepine derivatives $\mathbf{8 0}$, a class of bicyclic nitrogeneous heterocyclic compounds. When $o$-phenylenediamine and a enolizable ketones were refluxed in $\mathrm{n}$-hexane in presence of boric acid for a specified time, 80 was furnished in excellent yields (Scheme 33). ${ }^{55}$ Aromatic and aliphatic ketones underwent the conversion with same efficiency. 
The same cyclocondensation reaction was reported by Gholap and Tambe using boric acid as a green acid catalyst in water at room temperature. ${ }^{56}$

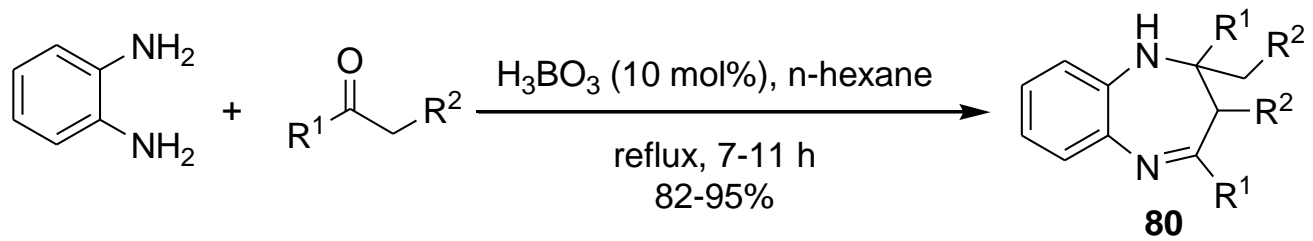

Scheme 33. Boric acid catalyzed synthesis of benzodiazepines.

16.5.3 Synthesis of fused thiazolopyrimidines. A facile and efficient protocol was reported by Meshram et al. for the synthesis of fused thiazolopyrimidines (81) in moderate to excellent yields by a reaction of a heterocyclic amine, $\beta$-keto ester and aldehydes, catalyzed by boric acid under eco-friendly conditions (Scheme 34). ${ }^{57}$

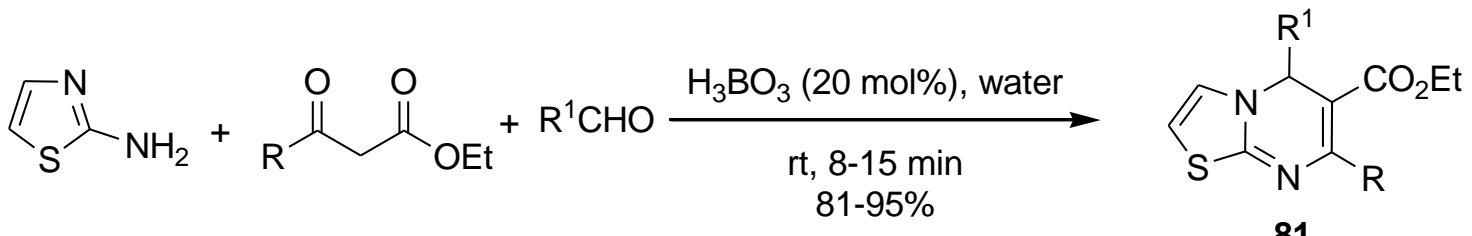

Scheme 34. Boric acid catalyzed synthesis of fused thiazolopyrimidines.

16.5.4 Synthesis of quinazolinones. Shaikh et al. worked on the synthesis of $[1,2,4]$ triazoloquinazolinone derivatives (82) by grinding method by the condensation of 3-amino-1,2,4-triazole, dimedone and aldehydes in presence of boric acid as a catalyst (Scheme 35$).{ }^{58}$

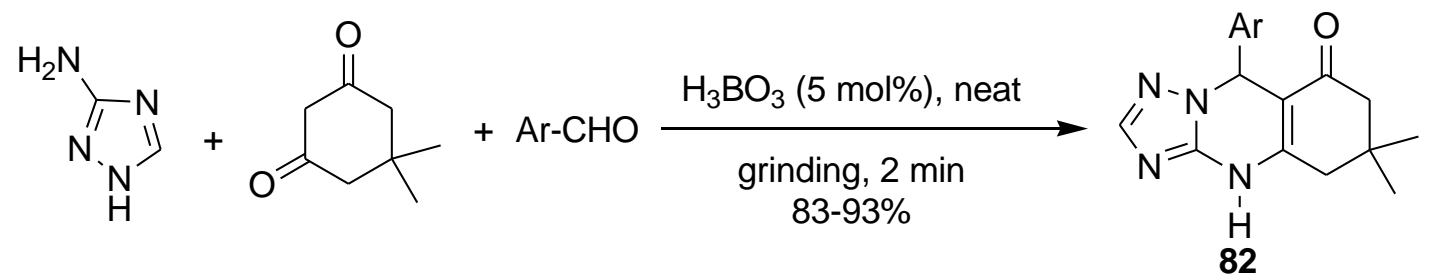

Scheme 35. Boric acid promoted synthesis of triazoloquinazolinones.

Karimi-Jaberi and Zarei (Scheme 36) ${ }^{59}$ demonstrated a simple, facile and efficient protocol for the synthesis of 2-substituted-2,3-dihydro-4(1H)-quinazolinones (83) with good yields from the reaction of 2-anthranilamide with aldehydes or ketones in presence of a catalytic amount of boric acid at $120^{\circ} \mathrm{C}$. 


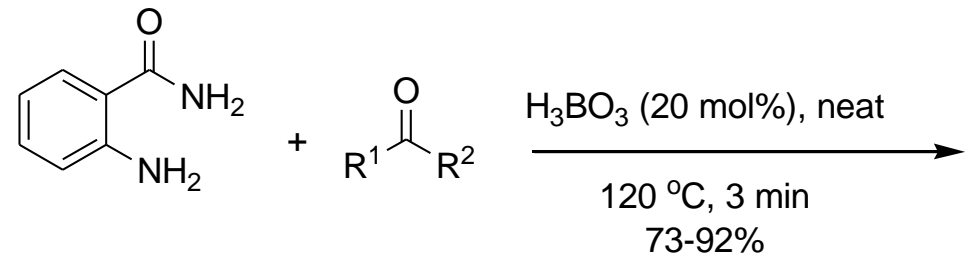

$73-92 \%$<smiles>[R]C1([R])NC(=O)c2ccccc2N1</smiles>

83

Scheme 36. Synthesis of 2,3-dihydro-4(1H)-quinazolinones in presence of boric acid.

16.5.5 Synthesis of imidazoles. Boric acid has also been used for the synthesis of Imidazole derivatives. Shelke and his group have synthesized a series of 2,4,5-triaryl-1H-imidazole derivatives $\mathbf{8 6}$ from benzil (84) or benzoin (85) with an aldehydes and ammonium acetate in aqueous medium under ultrasound at room temperature in excellent yields (Scheme 37). ${ }^{60}$

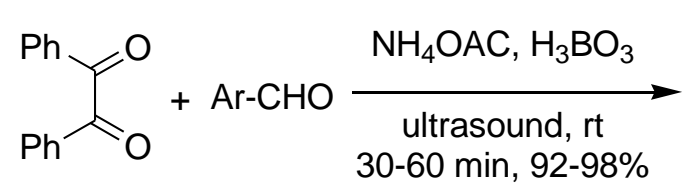

84<smiles>[Al]c1nc(-c2ccccc2)c(-c2ccccc2)[nH]1</smiles>

86

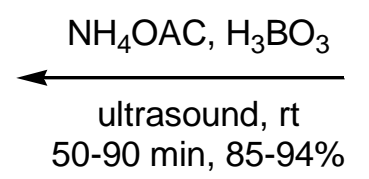

50-90 $\min , 85-94 \%$<smiles>O=C[C+][C+]C(O)c1ccccc1</smiles>

85

Scheme 37. Boric acid catalyzed synthesis of imidazoles under ultrasound-irradiation.

16.5.6 Synthesis of pyridines. Substituted pyrimidines $\mathbf{8 7}$, were also synthesized by using boric acid. Shinde et al. reported a condensation reactions of an aldehyde, malononitrile and thiophenol using boric acid and CTAB in water under conventional and ultrasound methods (Scheme 38). ${ }^{61}$ The reaction was proposed to proceed via the Knoevenagel condensation of an aldehyde and malononitrile, followed by the Michael addition of second molecule of malononitrile onto the Knoevenagel product. This then reacts with thiophenol and undergoes air oxidation to afford 87.

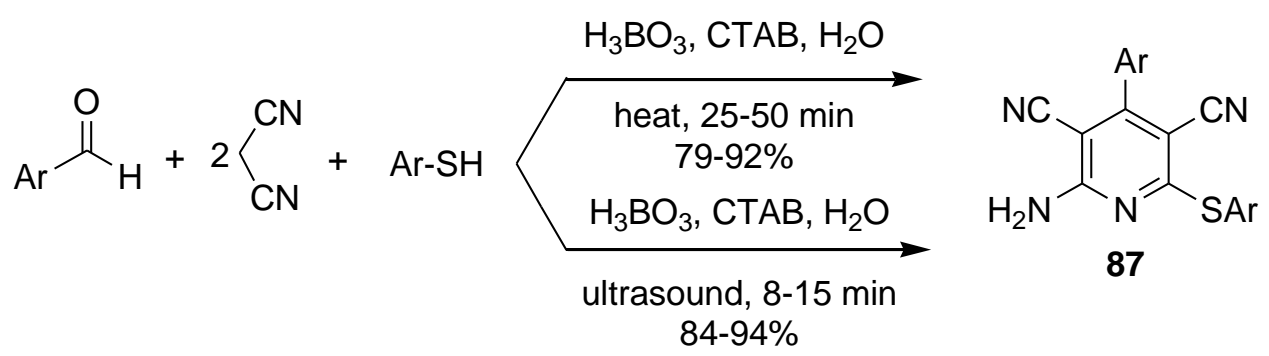

Scheme 38. Boric acid catalyzed synthesis of 2-amino-6-(arylthio)pyridine-3,5-dicarbonitriles in aqueous medium.

Karimi-Jaberi and Ghasemi designed the synthesis of imidazo[1,2-a]pyridine derivatives (88) from the onepot three-component condensation reaction of aromatic aldehydes, 2-aminopyridines and cyclohexylisocyanide using boric acid catalyst under solvent-free conditions (Scheme 39). 

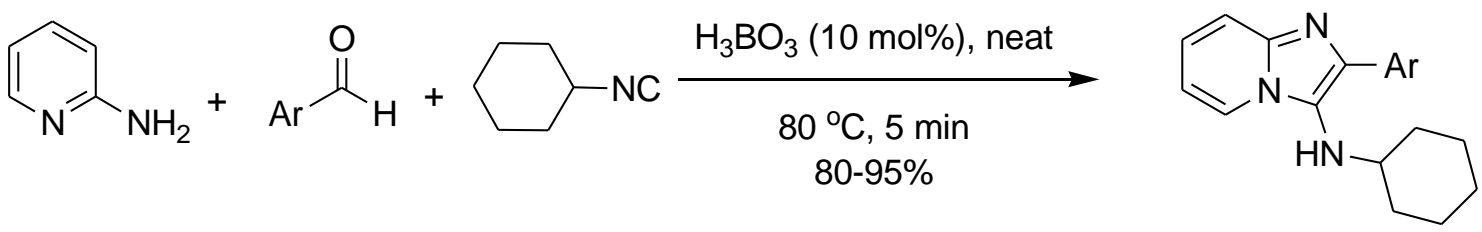

88

Scheme 39. Synthesis of imidazo[1,2-a]pyridine derivatives catalyzed by boric acid.

\subsection{Formation of oxygen heterocycles}

Oxygen heterocycles also represent a very important class of biologically active compounds. Xanthenes show antiviral and antibacterial activities, ${ }^{63}$ and benzopyrans form the backbone of many natural products and are also present in the recently discovered HIV inhibitory class of benzotripyrans. ${ }^{64}$ These oxygen heterocycles may be synthesized by using boric acid as catalysts.

16.6.1 Synthesis of dibenzoxanthenes. Karimi-Jaberi and Keshavarzi developed a simple and reliable method for the direct construction of biologically active 14-substituted-14H-dibenzo[ $a, j] x a n t h e n e s(89)$ in high yield from a one-pot condensation of $\beta$-naphthol with aldehydes in presence of boric acid under solvent-free conditions (Scheme 40). ${ }^{65}$ The mechanism of this reaction includes the initial generation of the carbocation, followed by the formation of aryl or alkyl methanebisnaphthols, which then undergo dehydration to give the final products.

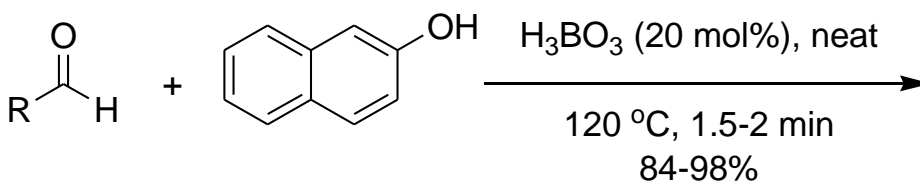

$84-98 \%$

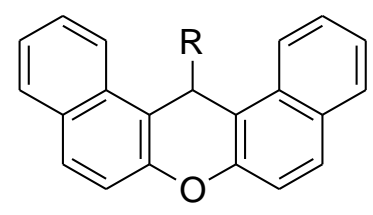

89

Scheme 40. Synthesis of dibenzoxanthenes using boric acid as catalyst.

16.6.2 Synthesis of benzopyrano-benzopyrans. Ganguly and his group found that boric acid can be utilized as a acid catalyst for the synthesis of 7-arylbenzopyrano[4,3-b]benzopyran-6,8-diones (90) by the three component reaction of 4-hydroxycoumarin, an aromatic aldehyde, and 5,5-dimethylcyclohexane-1,3-dione (dimedone) under aqueous micellar conditions (Scheme 41). ${ }^{66}$ Good to excellent yields, high selectivity, and green features including avoidance of organic solvent in the reactions and in the isolation stage and the use of a nontoxic water-compatible Lewis acid catalyst are key attractive features of the protocol.

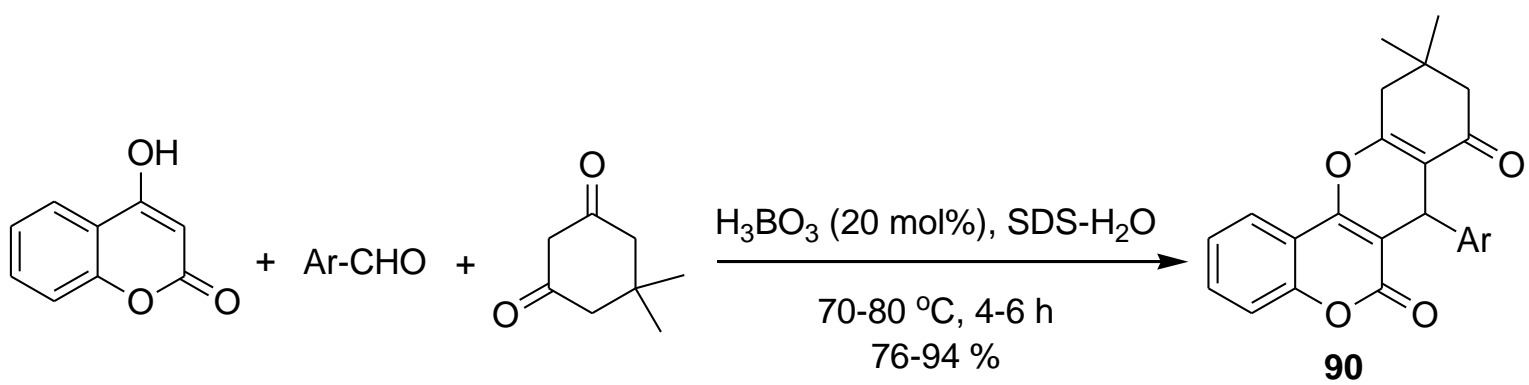

Scheme 41. Boric acid catalyzed synthesis of benzopyrano-benzopyrans. 


\section{Other Reactions}

\subsection{Synthesis of isoxazolinones}

Very recently, Klyani and Ghorbani have reported the preparation of $4 \mathrm{H}$-isoxazol-5-ones (91) from aryl aldehyde, $\beta$-keto ester and hydroxylamine hydrochloride in water at room temperature using boric acid as a catalyst (Scheme 42). ${ }^{67}$

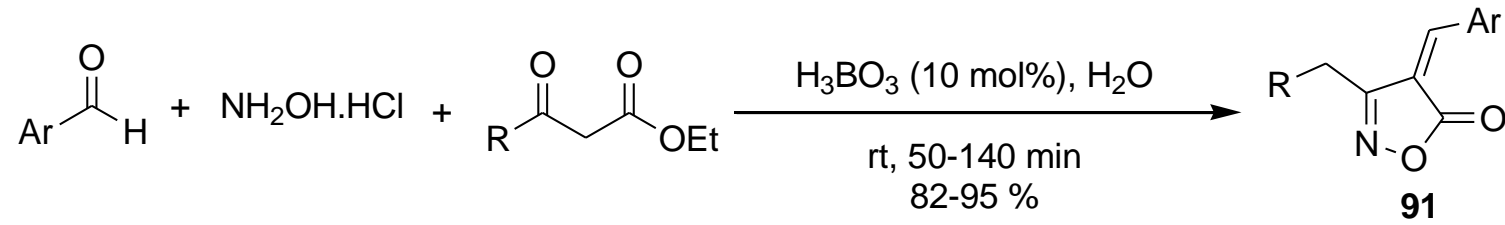

Scheme 42. Boric acid catalyzed synthesis of isoxazolinones.

A plausible mechanism for the formation of compound 91 was also investigated. The mechanism highlights the formation and role of $\mathrm{H}_{3} \mathrm{O}^{+}$and the possible involvement of the oxime intermediate, $\mathrm{B}$. Knovenagel condensation between the intermediate $B$ and aromatic aldehyde followed by a intramolecular cyclization leads to the product. Therefore the formation of the title compound via the intramolecular cyclilization intermediacy of Knoevenagel adduct $\mathbf{D}$ of the performed oxime of ethyl acetate followed by ring closure in the presence of boric acid.
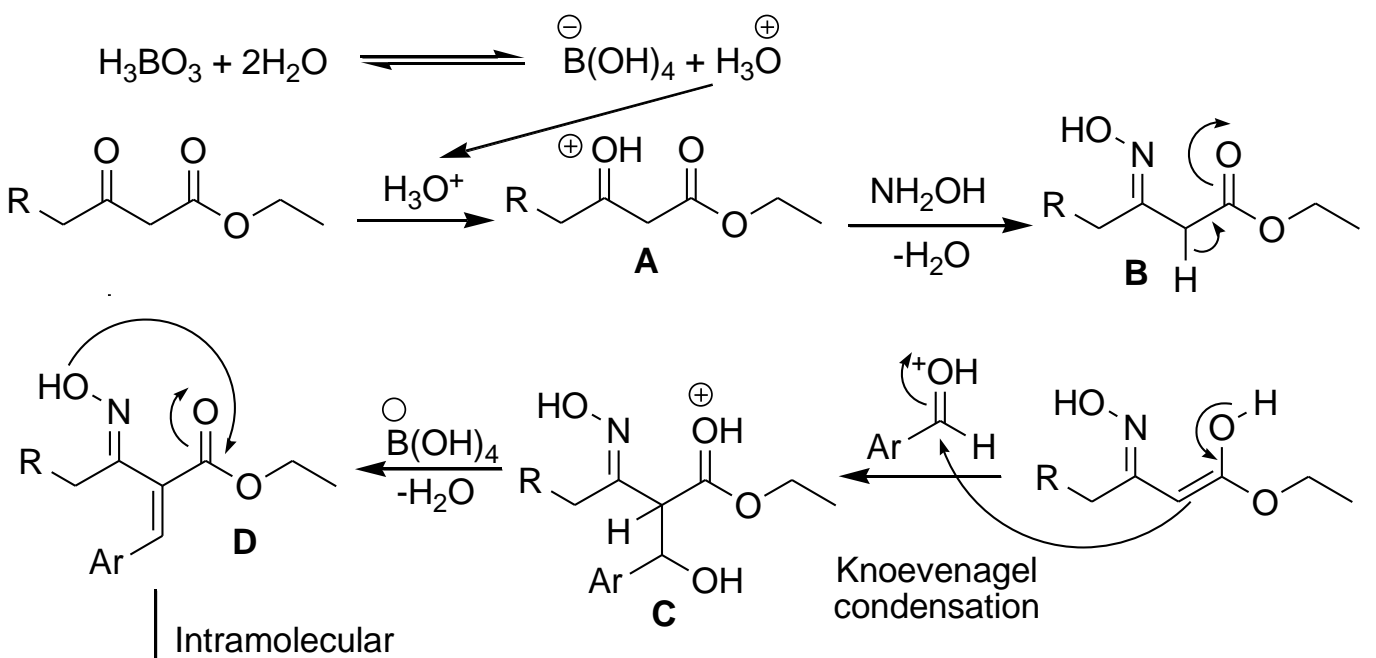
cyclization

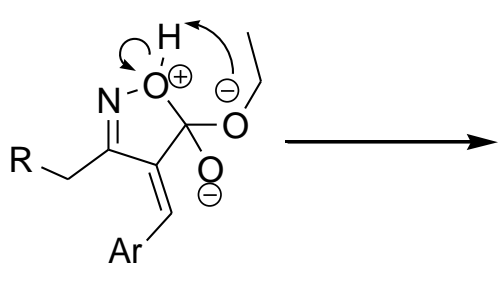

E

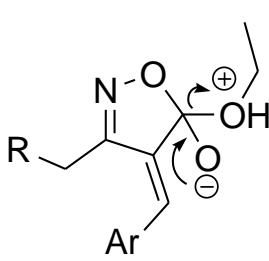

$\mathbf{F}$

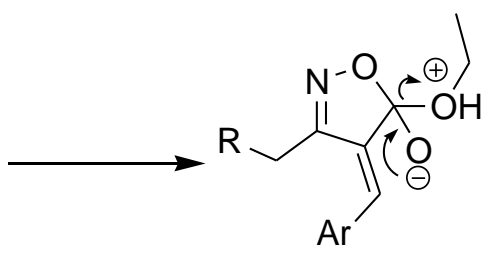

91

Scheme 43. Proposed mechanism for formation of of isoxazolinones catalyzed by boric acid. 


\subsection{Synthesis of $\alpha$-aminophosphonates and $\alpha$-aminonitriles}

A facile, one-pot three-component boric acid catalyzed condensation reaction between aldehydes, amines and trimethyl phosphite was developed by Karimi-Jaberi and Amiri ${ }^{68}$ for the synthesis of a series of $\alpha$ aminophosphonates (92) in good to excellent yields at room temperature under solvent-free condition (Scheme 44).
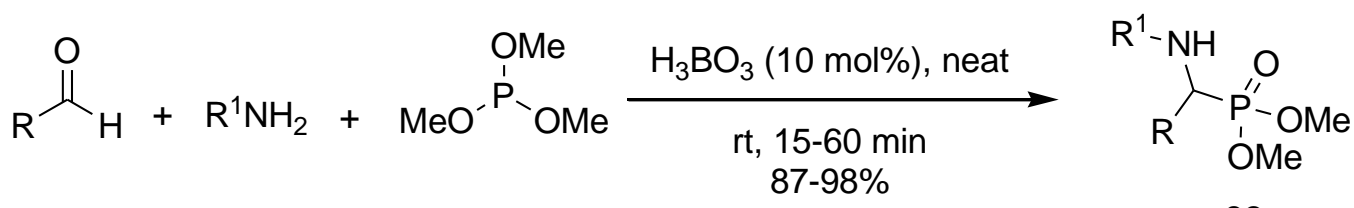

92

Scheme 44. Boric acid catalyzed synthesis of $\alpha$-aminophosphonates.

Karimi-Jaberi and his co-worker ${ }^{69}$ developed another boric acid catalyzed protocol for the synthesis of $\alpha$ aminonitriles (93) in a one-pot three-component condensation reaction of aldehyde, aromatic amine and trimethylsilyl cyanide at room temperature under stirring condition (Scheme 45).

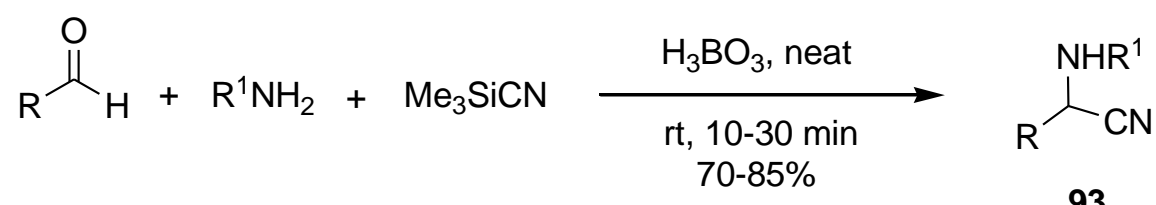

Scheme 45. Synthesis of $\alpha$-aminonitriles catalyzed by boric acid.

\subsection{Synthesis of 1-amidoalkyl-2-naphthols}

A series of 1-amidialkyl-2-naphthols (94) have been synthesized in good yields in a multi-component, one-pot condensation reaction of 2-naphthol, aldehydes and amides in presence of boric acid under neat conditions $\left(\right.$ Scheme 46) ${ }^{70}$.
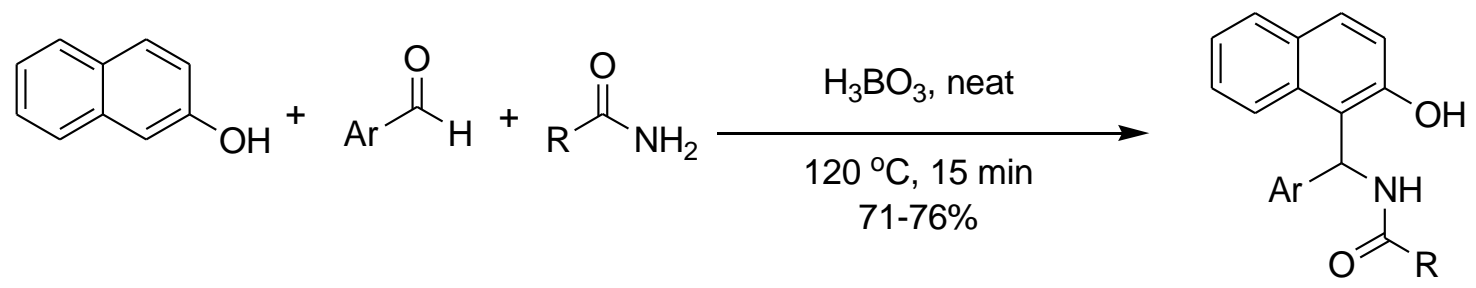

94

Scheme 46. Boric acid promoted synthesis of 1-amidoalkyl-2-naphthols.

\section{Conclusions}

This review gives an overview of active current interests in the synthetic applications of boric acid as catalyst. This growing interest of boric acid is mainly due to its very useful acidic properties, combined with its benign 
environmental character, cost effectiveness and commercial availability. There has been a major surge in activity in several areas of catalytic boric acid chemistry. These areas encompass the applications of boric acid in various organic transformations such as formation of $\mathrm{C}-\mathrm{C}, \mathrm{C}-\mathrm{N}, \mathrm{C}-\mathrm{O}$ and $\mathrm{C}-\mathrm{S}$ bonds in different synthetically important compounds. It is considered that the present review will make an impact on the on-going development of boric acid catalyzed organic transformations as it is one of the thrusting areas for today's organic methodologists world wide.

\section{Acknowledgements}

The author gratefully acknowledges the financial support from the University Grant Commission, New Delhi, Government of India (UGC MRP Grant no. PSW-055/15-16 (ERO) dated: 27.06.17).

\section{References}

1. Lowrance, W. W. Tetrahedron Lett. 1971, 37, 3453-3454. https://doi.org/10.1016/S0040-4039(01)97203-X

2. Houston, T. A.; Wilkinson, B. L.; Blanchfield, J. T. Org. Lett. 2004, 6, 679-681. https://doi.org/10.1021/ol036123g

3. Levonis, S. M. ; Pappin, B. B, ; Sharp, A. ; Kiefel, M. ; Houston, T. A. Aust. J. Chem. 2014, 67, 528-530. https://doi.org/10.1071/CH13459

4. Alemdar, N.; Erciyes, A. T.; Bicak, N. Polymer 2010, 51, 5044-5050. https://doi.org/10.1016/i.polymer.2010.08.066

5. Kondaiah, G. C. M.; Reddy, L. A.; Babu, K. S.; Gurav, V. M.; Huge, K. G.; Bandichhor, R.; Reddy, P. P.; Bhattacharya, A.; Anand, R. V. Tetrahedron Lett. 2008, 49, 106-109. https://doi.org/10.1016/j.tetlet.2007.11.008

6. Halimehjnai, A. Z.; Hosseyni, S.; Gholami, H.; Hashemi, M. M. Synth. Commun. 2013, 43, $191-197$. https://doi.org/10.1080/00397911.2011.594930

7. Chaudhuri, M. K.; Hussain, S.; Kantam, M. L.; Neelima, B. Tetrahedron Lett. 2005, 46, 8329-8331. https://doi.org/10.1016/i.tetlet.2005.09.167

8. Chaudhuri, M. K.; Hussain, S. J. Mol. Catal. A: Chem. 2007, 269, 214-217. https://doi.org/10.1016/j.molcata.2007.01.014

9. Wang, S.-Y.; Ji, S.-J.; Loh, T.-P. Synlett 2003, 2377-2379.

10. Das, B. C.; Marrippan, G.; Saha, S.; Bhowmik, D.; Chiranjib J. Chem. Pharm. Res. 2010, 2, 113-120.

11. Pal, R.; Mandal, T. K.; Mallik, A. K. J. Indian Chem. Soc. 2009, 86, 402-405.

12. Pal, R.; Mandal, T. K.; Mallik, A. K. J. Indian Chem. Soc. 2010, 87, 711-715.

13. Shiri, M.; Zolfigol, M. A.; Kruger, H. G.; Tanbakouchian, Z. Chem. Rev. 2010, 110, 2250-2293. https://doi.org/10.1021/cr900195a

14. Brun, E.; Safer, A.;Carreaux, F.; Bourahla, K.; L'helgoua'ch, J.-M.; Bazureau, J.-P.; Villalgordo, M. Molecules 2015, 20, 11617-11631.

https://doi.org/10.3390/molecules200611617

15 Offenhauer, R. D.; Nelsen, S. F. J. Org. Chem. 1968, 33, 775-777. https://doi.org/10.1021/jo01266a059

16. Meshram, H. M.; Rao, N. N.; Thakur, P. B.; Reddy, B. C.; Ramesh, P. Indian J. Chem. 2013, 52B, 814-817. 
17. Yadav, J. S.; Gupta, M. K.; Jain, R.; Yadav, N. N.; Reddy, B. V. S. Monatsh. Chem. 2010, 141, $1001-1004$. https://doi.org/10.1007/s00706-010-0355-8

18. Kumar, V.; Singh, C.; Sharma, U.; Verma, U.; Singh, B.; Kumar, N. Indian J. Chem. 2014, 53B, 83-89.

19. Pratibha, K. Res. J. Chem. Sci. 2014, 4, 58-62.

20. Singhal, A. ;Singh, S. ; Chauhan, S. M. S. Arkivoc 2016, vi, 144-151.

https://doi.org/10.24820/ark.5550190.p009.847

21. Marsi, K. L.; Wilen, S. H. J. Chem. Edu. 1963, 40, 214-215.

https://doi.org/10.1021/ed040p214

22. Meshram, H. M.; Rao, N. N.; Kumar, G. S. Synth. Commun. 2010, 40, 3496-3500.

https://doi.org/10.1080/00397910903457316

23. Garimallaprabhakaran, A.; Harmata, M. Synlett 2011, 61-64.

24. Stapp, P. R. J. Org. Chem. 1973, 38, 1433-1434.

https://doi.org/10.1021/jo00947a049

25. Nath, J.; Chaudhuri, M. K. Green Chem. Lett. Rev. 2008, 1, 223-230.

https://doi.org/10.1080/17518250902758887

26. Gogoi, K.; Dewan, A.; Gogoi, A.; Borah, G.; Bora, U. Heteroatom Chem. 2014, 25, 127-130. https://doi.org/10.1002/hc.21138

27. Delbecq, P.; Celerier, J.-P.; Lhommet, G. Tetrahedron Lett. 1990, 31, 4873-4874. https://doi.org/10.1016/S0040-4039(00)97756-6

28. Green, T. W.; Wuts, P. G. M. Protective Groups in Organic Synthesis, 2nd Edn.; Wiley: New York, 1991.

29. Kocienski, P. J. Protecting Groups, 3rd Edn.; Georg Thieme Verlag: Stuttgart, New York, 1994, pp. 50-71.

30. Rostami, A.; Akradi, J.; Ahmad-Jangi, F. J. Bra. Chem. Soc. 2010, 21, 1587-1592. https://doi.org/10.1590/S0103-50532010000800026

31. Ghose, A. K.; Viswanadhan, V. N.; Wendoloski, J. J. J. Com. Chem. 1999, 1, 55-68. https://doi.org/10.1021/cc9800071

32. Bhattacharya, A.; Bandichhor, R. Green Technologies in the Generic Pharmaceutical Industry. In Green Chemistry in the Pharmaceutical Industry, Dunn, P.; Wells, A.; Williams, M. T., Eds.; Wiley-VCH, Weinheim, 2011, Chapter 14, pp 289-309.

33. Tang, P. Org. Synthesis 2005, 81, 733-740.

34. Aree, G.; Carrau, G.' Bellomo, A.; Gonzalez, D. World J. Chem. Edu. 2015, 3, 27-29.

35. Mylavarapu, R. K.; Kondaiah, G. C. M.; Kolla, N.; Veeramalla, R.; Koikonda, P.; Bhattacharya, A.; Bandichhor, R. Org. Proc. Res. Dev. 2007, 11, 1065-1068.

https://doi.org/10.1021/op700098w

36. Harichandran, G.; Amalraj, S. D.; Shanmugam, P. J. Iran Chem. Soc. 2011, 8, 298-305. https://doi.org/10.1007/BF03246228

37. Nguyen, T. B.; Sorres, J.; Tran, M. Q.; Ermolenko, L.; Al-Mourabit, A. Org. Lett. 2012, 14, 3202-3205. https://doi.org/10.1021/ol301308c

38. Lu. J.; Bai, Y. Synthesis 2002, 466-470. https://doi.org/10.1055/s-2002-20956

39. Sarada, T.; Kobayashi, F. Sakai, N.; Konakahara, T. Org. Lett. 2009, 11, 2161-2164.

40. Eckert, H. Molecules 2012, 17, 1074-1102. https://doi.org/10.3390/molecules17011074

41. Kumar, A.; Saxena, D.; Gupta, M. K. RSC Adv. 2013, 3, 4610-4612.

https://doi.org/10.1039/c3ra23087b 
42. Mukhopadhyay, C.; Datta, A.; Butcher, R. J. Tetrahedron Lett. 2009, 50, 4246-4250. https://doi.org/10.1016/i.tetlet.2009.04.135

43. Tu, S.-J.; Zhu, X.-T.; Fang, F.; Zhang, X.-J.; Zhu, S.-L.; Li, T.-J.; Shi, D.-Q.; Wang, X.-S.; Ji, S.-J. Chin. J. Chem. 2005, 23, 596-598.

https://doi.org/10.1002/cjoc.200590596

44. Tu, S.; Fang, F.; Miao, C.; Jiang, H.; Feng, Y.; Shi, D.; Wang, X. Tetrahedron Lett. 2003, 32, 6153-6155. https://doi.org/10.1016/S0040-4039(03)01466-7

45. Karimi-Jaberi, Z.; Mohammadi, K. Sci. World J. 2012, Article ID: 925617, 4 pages.

46. Roth, T.; Morningstar, M. L.; Boyer, P. L.; Hughes, S. H.; Buckheit, Jr. W.; Michejda, C. J. J. Med. Chem. 1997, 40, 4199-4207. https://doi.org/10.1021/jm970096g

47. Schutz, H. Benzodiazepines, Springer, Heidelberg, 1982, vol. 2, p. 240. https://doi.org/10.1007/978-3-642-68426-5

48. Atwal, K. S.; Moreland, S. Bioorg. Med. Chem. Lett. 1991, 1, 291-294. https://doi.org/10.1016/S0960-894X(01)80810-6

49. Alagarsamy, V.; Revathi, R.; Meena, S.; Ramasheshu, K. V.; Rajashekam, S.; De Clercq, E. Indian J. Pharm. Sci. 2004, 66, 459-462.

50. Hunkeler, W.; Mohler, H.; Pieri, L.; Polc, P.; Bonetti, E. P.; Cumin, R.; Schaffner, R.; Haefely, W. Nature 1981, 290, 514-516.

https://doi.org/10.1038/290514a0

51. Reddy, T. R. K.; Mutter, R.; Heal, W.; Guo, K.; Gillet, V. J.; Pratt, S.; Chen, B. J. Med. Chem. 2006, 49, 607615.

https://doi.org/10.1021/jm050610f

52. Rajale, T.; Patil, D. D. J. Pharm. Sci. Biosci. Res. 2015, 5, 479-486.

53. Heravi, M. R. P.; Ashori, M. J. Chem. 2013, Article ID: 496413, 5 pages.

54. Maras, N.; Kocevar, M. Hel. Chimica Acta. 2011, 94, 1860-1874. https://doi.org/10.1002/hlca.201100064

55. Zhou, X.; Zhang, M. Y.; Gao, S. T.; Ma, J. J.; Wang, C.; Liu, C. Chin. Chem. Lett. 2009, 20, 905-908. https://doi.org/10.1016/i.cclet.2009.03.033

56. Gholap, S. S.; Tambe, G. B. RJC Rasayan J. Chem. 2008, 1, 862-864.

57. Meshram, H. M. ; Kumar, A. S. ; Kumar, G. S. ; Sweta, A. ; Reddy, B. C. ; Ramesh, P. Der Pharm. Chemica. 2012, 4, 956-960.

58. Shaikh, K. A.; Kande, S. R.; Khillare, C. B. IOSR J. Appl. Chem. 2014, 7, 54-58.

59. Karimi-Jaberi, Z.; Zarei, L. S. Afr. J. Chem. 2012, 65, 36-38.

60. Shelke, K. F.; Sapkal, S. B.; Sonar, S. S.; Madje, B. R.; Shingate, B. B.; Shingare, M. S. Bull. Korean Chem. Soc. 2009, 30, 1057-1060. https://doi.org/10.5012/bkcs.2009.30.12.2883

61. Shinde, P. V.; Sonar, S. S.; Shingate, B. B.; Shingare, M. S. Tetrahedron Lett. 2010, 51, 1309-1312. https://doi.org/10.1016/i.tetlet.2009.12.146

62. Karimi-Jaberi, Z.; Ghasemi, E. Chem. Biol. Interface 2017, 7, 224-229.

63. Ion, R.-M.; Planner, A.; Wiktorowicz, K.; Frackowiak, D. Acta Biochim. Pol. 1998, 45, 833-845.

64. Tang, Y.; Oppenheimer, J.; Song, Z.; You, L.; Zhang, X.; Hsung, R. P. Tetrahedron 2006, 62, 10785-10813. https://doi.org/10.1016/i.tet.2006.08.054 
65. Karimi-Jaberi, Z.; Keshavarzi, M. Chin. Chem. Lett. 2010, 21, 547-549. https://doi.org/10.1016/i.cclet.2010.01.014

66. Ganguly, N. C; Roy, S.; Mondal, P. Synth. Commun. 2014, 44, 433-440. https://doi.org/10.1080/00397911.2013.813546

67. Klyani, H.; Ghorbani, F. Res. Chem. Intermed. 2015, 41, 2653-2664. https://doi.org/10.1007/s11164-013-1411-x

68. Karimi-Jaberi, Z.; Amiri, M. Heteroat. Chem. 2010, 21, 96-98. https://doi.org/10.1002/hc.20577

69. Karimi-Jaberi, Z.; Abdolaziz, B. J. Chem. Res. 2012, 36, 326-327. https://doi.org/10.3184/174751912X13352842814921

70. Karimi-Jaberi, Z.; Fakhraei, H. Bull. Chem. Soc. Ethiop. 2012, 26, 473-478. https://doi.org/10.4314/bcse.v26i3.18

\section{Author's Biography}

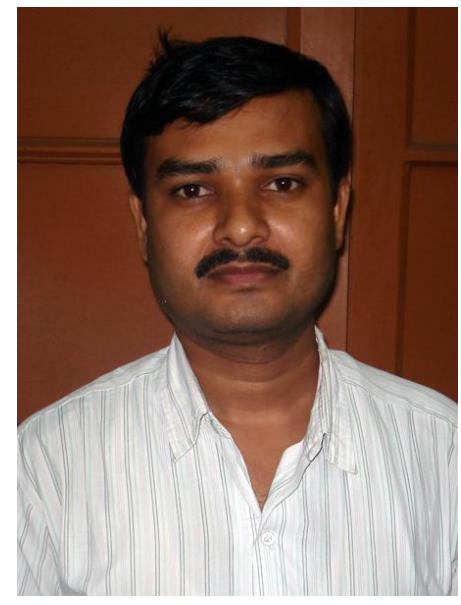

Rammohan Pal was born in 1978. His B.Sc. (1999) and M.Sc. (2001) were earned at University of Calcutta, India. He worked as a DBT-project fellow at the Biological Department of Chemistry, Indian Association for the Cultivation of Sciences (IACS), Kolkata and as a UGC-JRF at the Natural Product Laboratory, Indian Institute of Chemical Technology (IICT), Hyderabad, India. He carried out his predoctoral research work at the Department of Chemistry, Jadavpur University and received his Ph.D. degree in 2011. Presently, he is an Assistant Professor of Organic Chemistry at the Acharya Jagadish Chandra Bose College, Kolkata, India. He has published over 34 research papers and 4 review articles. His scientific interests lie in the fields of synthetic methodology, green chemistry and synthesis of nitrogen-containing heterocyclic compounds. 